DOI:10.24275/uama.7021.7517

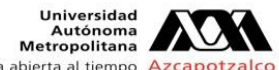

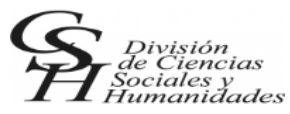 \\ Hhumanidades Massria nL Literatura $M$ \\ UNIVERSIDAD AUTÓNOMA METROPOLITANA \\ UNIDAD AZCAPOTZALCO \\ División de Ciencias Sociales y Humanidades \\ Maestría en Literatura Mexicana Contemporánea
}

\title{
DRAMATURGIAS Y FEMINICIDIOS
}

\author{
INFORME
}

Que para la obtención del grado de

\author{
Maestra en Literatura Mexicana Contemporánea \\ Presenta \\ Alejandra Gutiérrez Rebelo \\ Asesores \\ Dr. Christian Sperling \\ Mtra. Rocío Judith Galicia Velasco \\ Lector \\ Dr. Antonio Marquet Montiel
}

Ciudad de México, septiembre de 2018

Este informe recibió financiamiento del Padrón Nacional de Posgrados de

Calidad del Conacyt 


\section{AGRADECIMIENTOS}

A la Universidad Autónoma Metropolitana por permitirme ser parte de esta gran institución.

Al Dr. Christian Sperling por su apoyo, confianza y paciencia para este proyecto, mi agradecimiento y mi respeto.

A la Mtra. Rocío Galicia por sus comentarios y asesoría.

Al Dr. Antonio Marquet por sus palabras de aliento, su asesoría, apoyo e interés en el proyecto, mi admiración y cariño.

A mis profesores de la Maestría y compañeros por sus comentarios y apoyo. Les aprecio y respeto a tod@s.

A todos los dramaturgos, actores, actrices, fotógrafos, diseñadores que formaron parte de Dramaturgias y Feminicidios, gracias por su apoyo y entusiasmo a este proyecto que lo hicieron suyo desde un principio.

Especialmente a Virginia Hernández, Alan Aguilar, Pilo Galindo y Demetrio Ávila por el apoyo y la confianza para difundir estos textos tan entrañables.

A mis padres y hermanos por estar siempre. Mil gracias por TODO.

A mi esposo y mi hijo los amo, con ustedes todo cobra sentido. 
Cuando una mujer muere, nos roban la esperanza a todos; en ellas se fragua el amor con el que se vestirán las calles de nuestra tierra.

La mujer es origen y destino y si borramos el origen, perderemos inevitablemente el destino. Demetrio Ávila 
Contenido

1. Introducción 5

2. El proyecto de difusión

3. Lecturas dramatizadas 11

Los trazos del viento 13

Lomas de Poleo 23

Sirenas de Río $\quad 34$

4. Difusión Dramaturgias y Feminicidios en medios electrónicos $\quad 45$

www.dramaturgiasyfeminicidios.com 45

Presentación de www.dramaturgiasyfeminicidios.com en la Universidad Autónoma de Ciudad Juárez

5. Consideraciones finales 56

6. Referencias $\quad 58$ 


\section{Introducción}

Dramaturgias y Feminicidios

En el presente informe detallaré las actividades que integraron el proyecto de difusión Dramaturgias y Feminicidios, esta iniciativa tuvo como propósito la difusión de obras dramáticas cuyo tema es el feminicidio en México. Las actividades de este proyecto fueron un ciclo de lecturas dramatizadas durante 2017 en el teatro Lola Cueto, el diseño de la página web www.dramaturgiasyfeminicidios.com y la participación en el Congreso de la Asociación Mexicana de Investigación Teatral en Ciudad Juárez, Chihuahua.

Leer teatro es un acto difícil porque el lector debe hacer uso de su imaginación para representar en su mente cómo se vería en un escenario el espectáculo teatral. Sin embargo, en un texto dramático son las voces de los personajes que dan cuenta de lugares, pensamientos y pesares. A diferencia de la narrativa, en el teatro no hay un narrador que nos brinde descripciones minuciosas de espacios, sentires y comentarios que esclarezcan situaciones en la historia. Si bien el teatro está pensado para su representación, no todos los textos dramáticos llegan a la puesta en escena.

La puesta en escena es un espectáculo en el que inciden director, actores, escenógrafos, músicos y artistas visuales, además de todos los elementos que constituyen la semiótica de una representación. La diferencia con una lectura dramatizada, y quizá uno de los grandes retos, es el uso mínimo de recursos, pues la voz y el lenguaje corporal de los actores deben dotar de toda la expresividad del texto dramático: las emociones, el sentido de las palabras, la cadencia con que se cuenta una historia o las variaciones de intensidad en los diálogos.

La lectura en voz alta permite la posibilidad de intimar con el público, pues toda la atención está focalizada en el trabajo actoral y corporal de los actores. La lectura dramatizada es un medio para ejercitar la dicción y la entonación en función de las características del personaje 
representado. El actor necesita del ensayo porque, si bien la memorización de los textos y los movimientos no son los exactos de un montaje, la capacidad expresiva sí tiene que serlo. Es por esta razón que decidí, como parte del proyecto de difusión, la inclusión de lecturas dramatizadas porque los textos seleccionados exigían un proceso complejo de análisis de personajes debido a que las obras de los dramaturgos Virginia Hernández, Alan Aguilar, Edeberto Galindo y Demetrio Ávila exponen los crímenes de odio hacia las mujeres que han alcanzado cifras exorbitantes en las últimas décadas.

Las voces en La ciudad de las moscas, Los trazos del viento, Lomas de Poleo y Sirenas de Río son de madres, de hijas, de trabajadoras, de maestras, de niñas, etcétera, que han muerto en el anonimato. Así que, desde el teatro, en este espacio de excepción se evidencia la corrupción, la indiferencia y la apatía de una sociedad indolente que se convierte en cómplice y en verdugo. 


\section{El proyecto de difusión}

Dramaturgias y Feminicidios es un proyecto de difusión planeado desde octubre de 2016 con la intención de desarrollar dos actividades durante mi formación en la Maestría en Literatura Mexicana Contemporánea en la Universidad Autónoma Metropolitana Azcapotzalco.

La primera fue un ciclo de Lecturas dramatizadas titulado "Alma desnuda. Dramaturgias y Feminicidios" y se llevó a cabo de febrero a noviembre de 2017. Las obras seleccionadas fueron Los trazos del viento de Alan Aguilar, Lomas de Poleo de Edeberto "Pilo" Galindo y Sirenas de Río de Demetrio Ávila, estos textos forman parte de la antología Hotel Juárez: Dramaturgia de Feminicidios publicada en 2008 por la Universidad Juárez del Estado de Durango. ${ }^{1}$ Si bien la selección de las obras que conformaron el corpus para la difusión no fue fácil, los criterios que se establecieron fueron las propuestas dramatúrgicas consideradas más interesantes.

Entre los criterios para la selección de estas tres obras destacan la complejidad de los personajes femeninos, pues en los tres textos las mujeres violentadas tienen identidad, son voces que emergen de una sociedad indolente a los hechos que se han normalizado. Otra de las razones por que preferí trabajar con estos textos es la construcción dramática: la indeterminación espacial en las tres obras permite que haya una coincidencia en los lugares en que las mujeres son brutalmente asesinadas.

En Los trazos del viento de Alan Aguilar la obra la constituyen monólogos de cada una de las protagonistas: Lucía, Elena y Laura, ellas narran fragmentos de su vida antes de llegar a la maquiladora, sin embargo, sus recuerdos y la melancolía no tienen respuesta debido a que nunca

\footnotetext{
${ }^{1}$ Las otras obras que conforman la antología son Justicia Light de Ernesto García, La ciudad de las moscas de Virginia Hernández, Mujeres de Ciudad Juárez de Cristina Michaus, Jauría de Enrique Mijares, Hotel Juárez de Víctor Hugo Rascón Banda, Desere (El Desierto) de Cruz Robles, Tlatoani (Las mujeres de Suárez) de Juan Tovar y Estrellas Enterradas de Antonio Zúñiga.
} 
hay una interacción entre ellas. La construcción de los personajes es una radiografía de sueños interrumpidos por el viento, es decir: una metáfora de la violencia que sufren las víctimas. El texto de Alan Aguilar me pareció interesante por el lenguaje poético en momentos de las tres mujeres, pues las descripciones de los lugares de origen, de la familia y de los seres queridos evocan imágenes que revelan realidades y significados sesgadas por la muerte.

En cuanto a Lomas de Poleo de Edeberto "Pilo" Galindo, su importancia radica en una estructura a partir de los lugares en donde se desarrolla la acción. Las protagonistas se encuentran en un limbo, éste evidencia la falta de identidad de las cuatro mujeres. Para Maty, Nancy, Erika y Angélica, la casa que habitan adquiere significados diversos a partir del desdoblamiento de personajes y de lugares que conviven en un mismo cuadro. La propuesta dramatúrgica de Pilo Galindo evoca a mujeres convertidas en cifras, en explotación laboral y, por supuesto, en una indiferencia por parte de las autoridades.

Por último, Sirenas de Río de Demetrio Ávila fue la última obra seleccionada para integrar el corpus de las lecturas dramatizadas. En este texto las voces de las sirenas emergen desde un río de sangre: todas son arrojadas a un río que borrará sus huellas, su humanidad, su rastro. El río es la representación de la corrupción y de la indiferencia. Las mujeres que han sido violadas, mutiladas y asesinadas son arrojadas al río como un trofeo para los victimarios.

Las tres obras que se presentaron en las lecturas dramatizadas son historias de horror cuya violencia ocupa no sólo un espacio teatral, sino social. Estas obras son apenas unas cuantas historias de miles y miles de otras.

El trabajo de selección no fue nada fácil, pues ¿cómo preferir un grito de auxilio o un grito de dolor? Lo que pretendí fue optar por personajes que resultaran entrañables para el público, extraer una muestra milimétrica de muchas historias en el anonimato. Voces que retornan del silencio, desde la soledad, desde la indiferencia en la que vivimos. 
La segunda actividad fue la creación de la página web www.dramaturgiasyfeminicidios.com cuyo objetivo es difundir los textos seleccionados, así como presentar videos, galerías de las lecturas dramatizadas y entrevistas que hice a los dramaturgos Alan Aguilar, Pilo Galindo, Demetrio Ávila y Virginia Hernández junto con sitios de interés sugeridos con el propósito de difundir algunas páginas informativas con artículos de investigación, notas periodísticas y reseñas de obras de teatro para quienes visiten la plataforma y deseen profundizar en el tema de los feminicidios.

En noviembre de 2016 comenté con mi asesor el Dr. Christian Sperling la posibilidad de un proyecto de difusión que tuviera como tema central el feminicidio en el teatro, pues mi formación académica teatral me permitía planear actividades que estuvieran relacionadas con las artes escénicas. A medida que avanzaba el primer trimestre, establecimos junto con mi coasesora, la Mtra. Rocío Galicia, la necesidad de organizar un proyecto de difusión masiva y especializada, pues el carácter del posgrado radica en desarrollar el pensamiento reflexivo y creativo en función del análisis y la crítica literaria, así que no podía dejar a un lado el análisis de los textos dramáticos.

El proyecto Dramaturgias y Feminicidios se estableció a partir de una serie de actividades que permitiera la difusión de las lecturas dramatizadas presentadas en el teatro Lola Cueto. Utilicé las redes sociales como una herramienta para establecer vínculos con el público interesado en asistir al ciclo "Alma Desnuda. Dramaturgias y Feminicidios". Las redes del proyecto son las siguientes:

$>$ Facebook: https://www.facebook.com/dramaturgiasyfeminicidios/

> YouTube: https://www.youtube.com/channel/UC2YkK_CLkNVW0m6Lkk4OIuA

$>$ Instagram: https://www.instagram.com/dramaturgiasyfeminicidios/

$>$ Correo electrónico: dramaturgiasyfeminicidios@gmail.com 
La difusión especializada del proyecto se estableció en la creación del sitio web

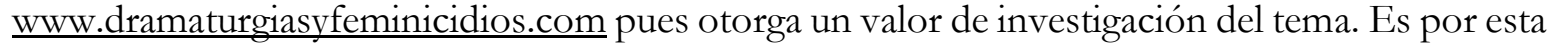
razón que el objetivo de la página web es crear contenido y material que aporte información y establezca vínculos con público que esté interesado en el tema.

Las lecturas dramatizadas, primera actividad, comenzó en febrero de 2017 en el teatro Lola Cueto ubicado en Francisco Sosa 298, recinto que amablemente nos proporcionó Pablo Cueto para las presentaciones hasta noviembre de ese año. Otro de los recintos en donde tuvimos la oportunidad de presentar las lecturas Lomas de Poleo y Sirenas de Río fue en julio y en noviembre, respectivamente, en la Universidad Autónoma Metropolitana Azcapotzalco gracias a las facilidades brindadas por el coordinador de la Maestría, el Dr. Christian Sperling. 


\section{Lecturas dramatizadas}

El teatro es más que una práctica discursiva: se reduce a una sola comprensión semiótica, los actores y directores llenan con su lectura e interpretación en la representación escénica los vacíos del texto dramático. En este espacio efímero no se muestra lo que es ni lo que debe ser, sino lo que puede ser; un ejemplo de esto es la posibilidad de recrear historias con una mirada microscópica de un fragmento de la realidad.

En el caso de Dramaturgias y Feminicidios, los textos seleccionados para trabajar en el proyecto de difusión hablan de trayectorias de vidas que cortaron los asesinatos. Las obras recrean la perspectiva de violencia ejercida en contra de las mujeres muestra para representar lo que puede ser a partir de fragmentos desgarradores y esperanzadores. Son dicotomías en un espacio extraordinario, son interrogantes que pueden hallar respuestas cuando es preciso hablar la violencia: ponerla en escena, pensarla y reflexionar en ella.

Por lo tanto, al referirme a la diversidad de interpretaciones o puestas en escena, es importante considerar que, entre las cualidades esenciales de lo teatral, se encuentra la posibilidad de generar un espacio y un tiempo de excepción. En este espacio extraordinario los problemas sociales, como el feminicidio en México, es tema que se encuentra inscrito en las artes escénicas que van desde la danza, el performance, la música y, por supuesto, el teatro.

La antropóloga e investigadora Marcela Lagarde es una de las personas que condenó estos crímenes de odio es y creó una Comisión Especial de Feminicidio en el Congreso para investigar el asesinato de mujeres en Ciudad Juárez. La también catedrática apunta que los feminicidios son aquellos que "ocurren de manera criminal en el silencio, la omisión, la negligencia y la colusión de autoridades". ${ }^{2}$ Por lo tanto, la falta de respuesta por parte de las autoridades son contadas en

\footnotetext{
${ }^{2}$ Marcela Lagarde y de los Ríos, "Antropología, feminismo y política: violencia feminicida y derechos humanos de las mujeres”, en Margaret Louise Buulen y María Carmen Díez Mintegui (coords.), Retos teóricos y nuevas prácticas,
} 
el teatro a partir de dramaturgias que exponen lo que puede ser, en consecuencia, éste es un tema que incomoda a las autoridades y a la sociedad mexicana.

A partir de esta reflexión, surge Dramaturgias y Feminicidios ya que al ingresar a la Maestría mi proyecto de tesis se refería a hacer un análisis comparativo de dos obras de teatro cuya temática radicaba en los feminicidios en México. Así que este tema, por desgracia tan actual y atroz, está presente en las artes escénicas desde hace más de 20 años.

Aun cuando no tenía la claridad de Dramaturgias y Feminicidios, pensé en quién podía ser parte del proyecto para trabajarlo durante un año, así que de inmediato pensé en Paolina Orta, ${ }^{3}$ amiga y compañera de la universidad, a quien le propuse en diciembre de 2016 integrarse a las lecturas dramatizadas, no sólo como actriz, sino como asistente de dirección, así que ambas pudimos hacer una calendarización provisional del ciclo de lecturas dramatizadas para su montaje durante el 2017.

En un principio del proyecto se planteó como un ciclo de lecturas de cinco obras, sin embargo, por cuestiones de tiempo y de logística, tuvieron que dejarse afuera Estrellas Enterradas de Antonio Zúñiga y La ciudad de las moscas de Virginia Hernández, textos que merecen especial atención por su acercamiento al tema feminicida desde la perspectiva de los victimarios y por

Ankulegi, San Sebastián (Esp.), 2008, pp. [216]. $\leq$ https://www.ankulegi.org/wpcontent/uploads/2012/03/0008Lagarde.pdf>. Consulta: 20 de junio de 2017.

${ }^{3}$ Egresada de la carrera de Literatura Dramática y Teatro en la Facultad de Filosofía y Letras de la UNAM. Becaria en 2018 del Fondo Nacional para la Cultura y las Artes. Ha tomado diversos talleres de manipulación de títeres, teatro y danza. Es actriz, titiritera y técnico en iluminación de la compañía Teatro Tinglado con la que se ha presentado en Guadalajara, Xalapa, Cali y Buenos Aires. En 2013 comienza la realización del proyecto Posada para el pueblo. Vida y muerte de Don Lupe, texto y dirección de su autoría con asesoría de Pablo Cueto y Edwin Salas. Formó, al lado de María Teresa Trentín, parte de la organización general del proyecto Tetas sin varilla en la Primera muestra de mujeres titiriteras en la Ciudad de México. Actualmente se encuentra en el montaje de teatro para títeres titulado Un relámpago apenas sobre cuatro poetas latinoamericanas: Alejandra Pizarnik, Claric Lispector, Rosario Castellanos y Delmira Agustini. 
una visión mítico-apocalíptica respectivamente. ${ }^{4} \mathrm{Si}$ bien el proceso de selección no fue fácil, Paolina y yo fuimos las encargadas de incorporar, como parte de la compañía que se estaba gestando para Dramaturgias y Feminicidios, a actores profesionales egresados de la Facultad de Filosofía y Letras de la UNAM y del Instituto Andrés Soler.

A continuación, presentaré el trabajo hecho para cada uno de las obras presentadas en las lecturas dramatizadas.

"Los trazos del viento" (1998), de Alan Aguilar

Los trazos del viento de Alan Aguilar es la historia de tres mujeres trabajadoras en una maquiladora en el norte del país. El regreso a casa y la búsqueda de la libertad son contadas a partir de pequeños monólogos evocadores de historias inconclusas de la infancia, del seno familiar y de la añoranza, en aquéllos se muestra la fragilidad de sus vidas como un recuerdo de su vida antes de llegar a la maquiladora. Alan Aguilar expone el rostro de estas mujeres en un espacio íntimo a partir de una casa modesta ambientada con fotos familiares; en el segundo acto, se muestran cómo sopla el viento en el exterior, aumenta su intensidad y el giro que toman las historias de cada una de las protagonistas.

Lucía, Laura y Elena recuerdan cómo era su vida antes de llegar a la maquiladora. Lucía, la niña de los canarios, recuerda a Mamá Mari y extraña tomarle de la mano para volver al mar;

\footnotetext{
${ }^{4} \mathrm{Al}$ ingresar a la Maestría, el proyecto de tesis con el que fui aceptada pretendía analizar la violencia feminicida en Lomas de Poleo de Pilo Galindo y Estrellas Enterradas de Antonio Zúñiga, este fue mi primer corpus para referirme al teatro y feminicidio con la asesoría de Rocío Galicia, quien es especialista en el tema.

Respecto a la obra de Virginia Hernández, tuve la oportunidad de entrevistar a la dramaturga a propósito del texto La ciudad de las moscas, así como la fortuna de tener un encuentro con ella en el Congreso de la Asociación Mexicana de Investigación Teatral en octubre de 2017 en la Universidad Autónoma de Ciudad Juárez, mismos lugar y fecha para la presentación de la página web www.dramaturgiasyfeminicidios.com.
} 
con este dato, puede deducirse que Lucía es originaria de algún estado del golfo porque muchas de las mujeres emigran desde esta zona a la frontera norte del país para trabajar a las maquilas. Para Lucía, sus canarios son sus confidentes, ya que el recuerdo de Mamá Mari y sus historias son una metáfora de la libertad condicionada que ella vive en la fábrica. Quizá para Lucía los canarios también han perdido la capacidad de ser libres pues "son canarios de jaula y ya se les olvido volar". ${ }^{5}$

Cada una de las protagonistas tiene un sobrenombre; narran la historia de vida que han dejado atrás para llegar a un lugar ajeno, un territorio yermo en el que sólo estarán por un tiempo o, al menos, ellas pretenden así sea. Lucía (la niña de los canarios), Laura (la niña de los niños); y Elena (la niña de las esferas) establecen un vínculo entre nombre e historia que apela respectivamente a la nostalgia, la dicha y la esperanza.

Laura, la niña de los niños, representa el amor maternal: es una madre soltera embarazada que tiene la ilusión de una mejor vida para su hijo. Laura es la voz de las trabajadoras que son madres y tienen que sortear su vida laboral con la familiar. Para Laura, su hijo es su confesor; aunque no ha nacido, ella le relata todo lo que harán cuando estén juntos, pues no pierde la esperanza de que quizá en un futuro la situación sea diferente: “Aunque me parta el lomo, eso es lo que hoy vi para ti. Un hogar donde todo sea diferente, donde no tengas que estar bajo las órdenes de una estúpida mamá y de un papá ausente que nada más llega para reclamar vida, porque se está muriendo" (65).

\footnotetext{
${ }^{5}$ Alan Aguilar, Los trazos del viento, en Enrique Mijares (ed.), Hotel Juárez: Dramaturgia de Feminicidios, presentación de Victoria Martínez y Rocío Galicia, Universidad Juárez del Estado de Durango, campus Durango-Espacio Vacío/Union College, 2008 (Colección Teatro de Frontera, 21-22), p. 64. En adelante se anotará el número de página del texto para las citas dentro de paréntesis.
} 
Elena, la niña de las esferas, es la más joven de las tres mujeres. Para ella, el trabajar en la maquila sólo es el paso para emigrar hacia Estados Unidos. Elena aspira a comprarse un coche en un lapso de seis meses para dejar el país; ella es la única que denuncia el acoso por parte de los hombres en la maquiladora, sus pensamientos no están en la nostalgia del pasado como los de Lucía, sino en un futuro prometedor, en otras tierras donde se cumplan los sueños: cruzar la frontera para "llegar a donde no me importe ninguna línea adelante" (69).

Para Alan Aguilar, Los trazos del viento es una denuncia y un homenaje a las víctimas de los feminicidios, por estos motivos, utiliza un lenguaje poético en la narración de cada una de las protagonistas. Aun cuando sus historias nunca se cruzan, estas mujeres comparten un espacio simbólico en el que se sienten seguras ajeno al espacio de la maquiladora: la casa. Ésta representa un primer universo en donde el recuerdo y la integración de sus sueños y pensamientos recrean su espacio íntimo.

Al leer el texto Paolina y yo, coincidimos en que esta obra sería la primera seleccionada porque requería solamente a tres actrices y la brevedad del texto nos permitiría un trabajo más personal con el elenco. En esa primera etapa, necesitábamos dos actrices que tuvieran la disposición para integrarse al proyecto, pero sin remuneración económica, solamente la cooperación voluntaria por parte del público el día de las funciones.

Por fortuna, las actrices que se sumaron a la primera etapa de Los trazos del viento fueron Mariana Ferreira ${ }^{6}$ y Lourdes Onofre ${ }^{7}$, con quienes hicetrabajo de mesa, es decir, análisis de los

\footnotetext{
6 Originaria de la Ciudad de México. Licenciada en Literatura Dramática y Teatro por la UNAM, artista multidisciplinaria y Ddocente de arte y teatro. Ha tomado cursos de arte, performance, instalación, videoarte y rediseño en Casa de Lago, de la UNAM, además del Diplomado de Arte Actual y Contemporáneo en el Cenart. Actualmente colabora en la revista Der Spiegel edición México como correctora de estilo e Information Manager.

7 Actriz, dramaturga y directora. Egresada del Instituto Andrés Soler en 2011. Ha participado como actriz en distintas compañías de teatro: Salida de Emergencia Teatro, Poblarin, Intelecto Artístico, Irreverente Teatro y Onirismos. Estuvo a cargo de la dirección de la puesta en escena para la compañía de teatro Los Exiliados de
} 
personajes correspondientes, contextualización de la obra y los feminicidios en México, además de puntualizar la importancia que tenía para mí este proyecto no sólo académico como parte de mi estancia en la Maestría, sino como una oportunidad de hacer patente desde el teatro una denuncia contra las atrocidades de los crímenes de odio hacia las mujeres en nuestro país.

En mi papel como directora, determiné la selección de los personajes con base en las características físicas y actorales de cada una de las actrices, es por esto que el elenco de la siguiente manera:

Paolina Orta: Lucía, niña de los canarios.

Mariana Ferreira: Laura, niña de los niños.

Lourdes Onofre: Elena, niña de las esferas.
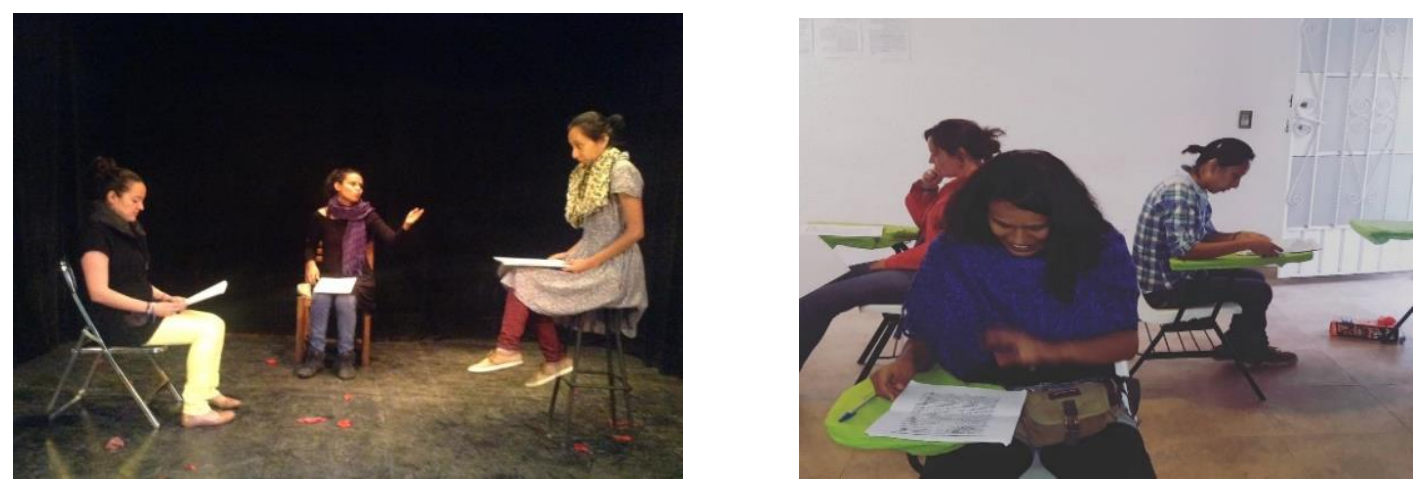

F1 y F2 Ensayo de Los trazos del viento

Para la lectura, se utilizaron elementos simbólicos como globos rojos que apelaban a los sueños y aspiraciones de las protagonistas y sillas distintas para diferenciar las historias que nunca se

Háblame como la lluvia y déjame escucharte de Tennesse Williams y El Gordo una adaptación libre del texto original de El Pleito de las Calaveras de Óscar Liera. Actualmente está a cargo de su compañía de teatro Compañía Teatral Reflejo Independiente. 
cruzan, aunque coinciden en tiempo o en espacio. Por esta razón, el mínimo de recursos escenográficos fue pensado desde un principio para que el trabajo actoral destacara en la lectura dramatizada.

La música de Los trazos del viento fue pensada para crear un ambiente íntimo; en el primer acto utilizamos para la entrada de público el audio del poema "We Teach Life, Sir!" de Rafeef Ziadah. En el segundo acto, la integración del sonido de un metrónomo tuvo la finalidad de crear un ambiente de tensión y culminó con la muerte de las protagonistas; mientras que para el final de la lectura incluimos la melodía "Vapor Barato" de Gal Costa para utilizarla como leitmotiv en ésta y las demás obras seleccionadas.

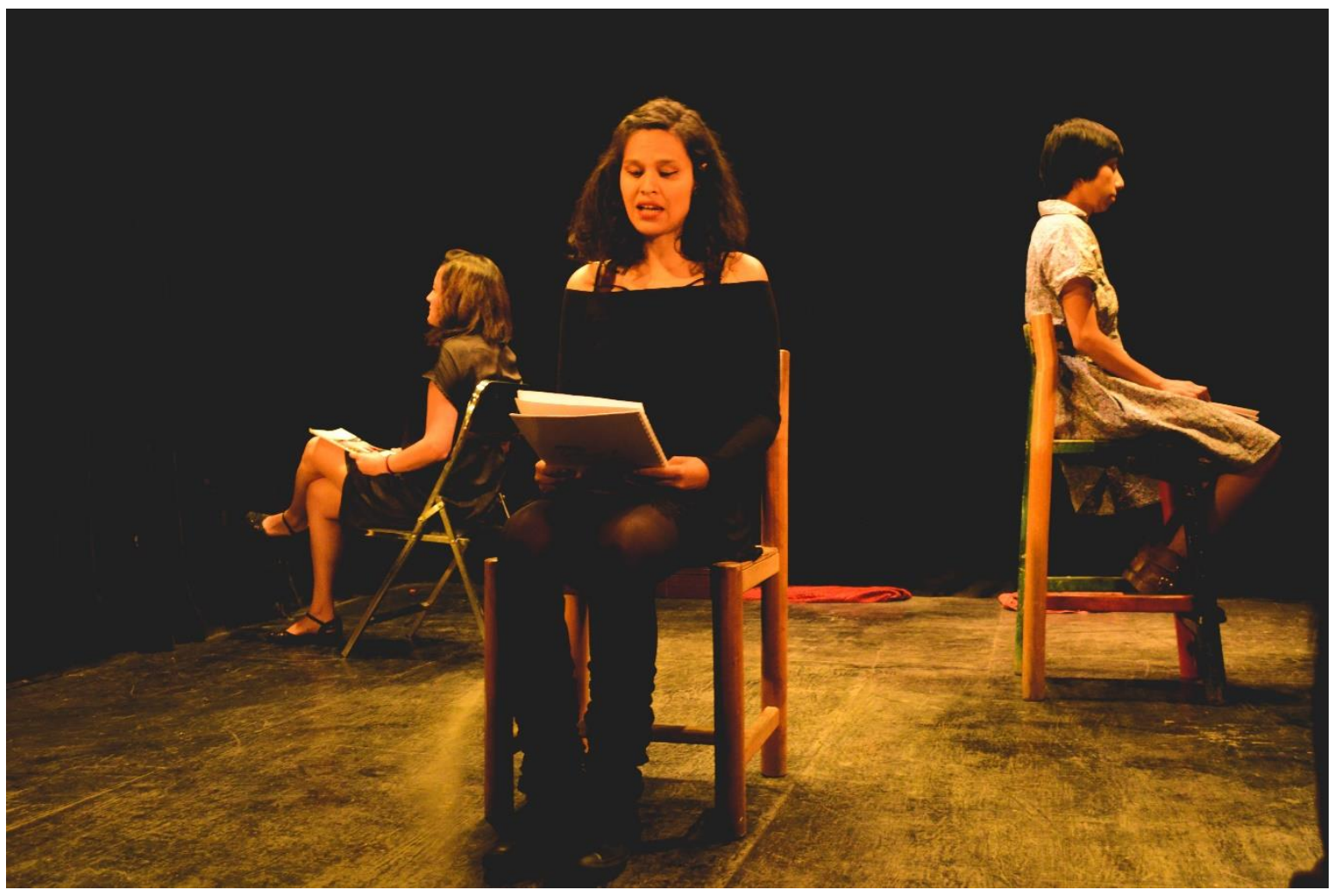

F3 Función de Los trazos del viento en el teatro Lola Cueto

Otro de los elementos a considerar en la puesta en escena fue la iluminación: en el primer acto se utilizaron luces ámbar para representar la casa con el fin de crear un ambiente cálido e íntimo. 
En el segundo acto, las luces utilizadas fueron azules para crear en las protagonistas el ambiente de desesperación y de angustia hasta la muerte de cada una. En la última escena de la lectura, sólo quedaban en escena los zapatos de las protagonistas, pues representaba los cuerpos no identificados de las mujeres que fueron violentadas y mutiladas.

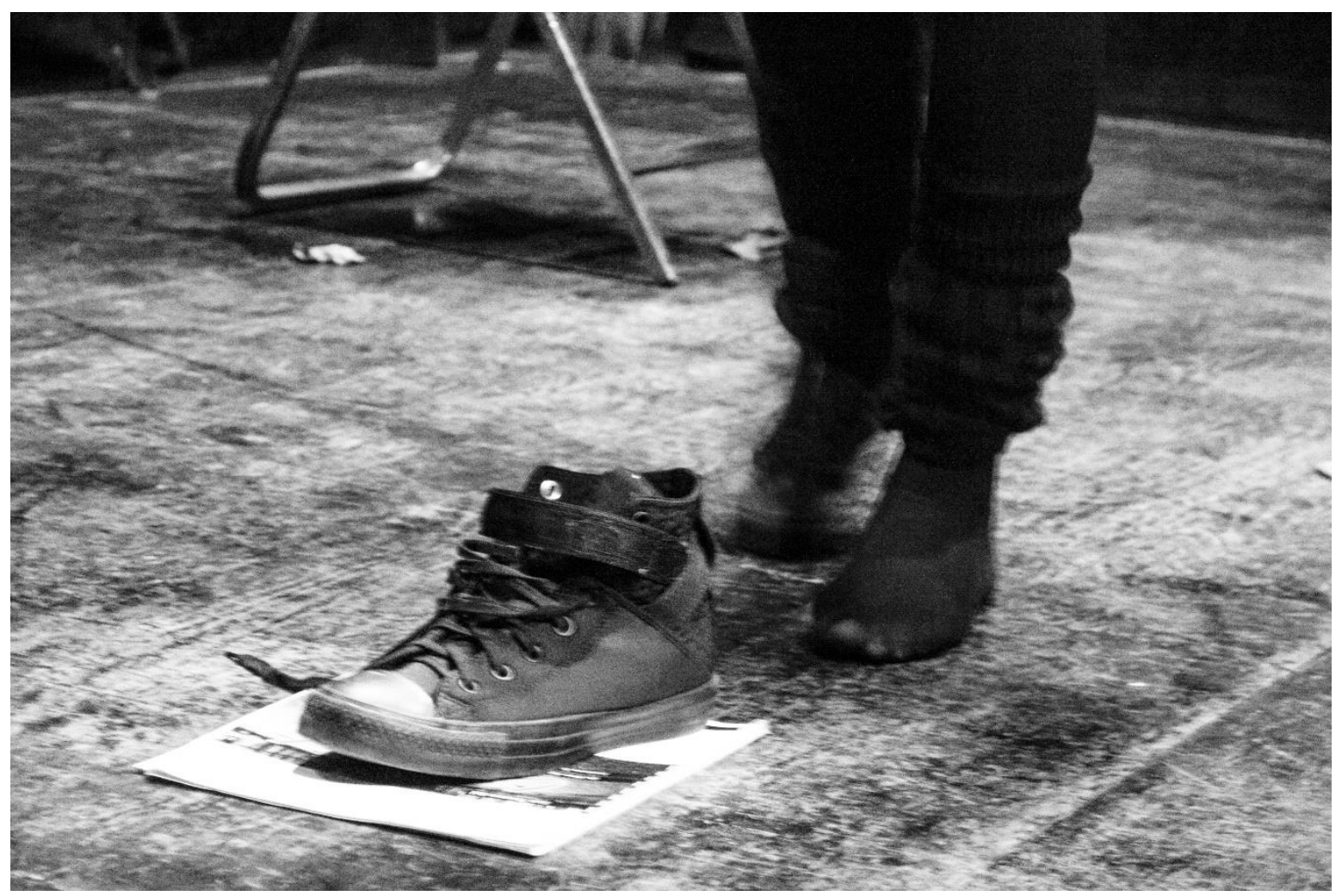

F4 Función de Los trazos del viento en el teatro Lola Cueto

En la primera etapa de Los trazos del viento, la lectura se presentó el 15 y 19 de febrero, 8 y 12 de marzo de 2017 en el teatro Lola Cueto. La recepción del público fue buena e incluso en algunas funciones hubo intercambio de opiniones respecto al texto y la violencia de género que se vive en nuestro país. Esta aceptación fue una de las razones para que buscáramos otros espacios para presentar la lectura dramatizada, así que amablemente se nos invitó a presentarla 15, 22 y 29 de 
junio en Laberinto Cultural Santa María. ubicado en Jaime Torres Bodet 259, Col. Santa María La Ribera.

En esta segunda etapa de Los trazos del viento, se integró la actriz Gabriela Espinosa, ${ }^{8}$ pues consideramos que sería una buena opción incorporar más actrices en el proyecto; sin embargo, las presentaciones en Laberinto Cultural Santa María no tuvieron la misma recepción que en Francisco Sosa porque la audiencia fue menor y el espacio no permitió crear la misma atmósfera lograda en Coyoacán.

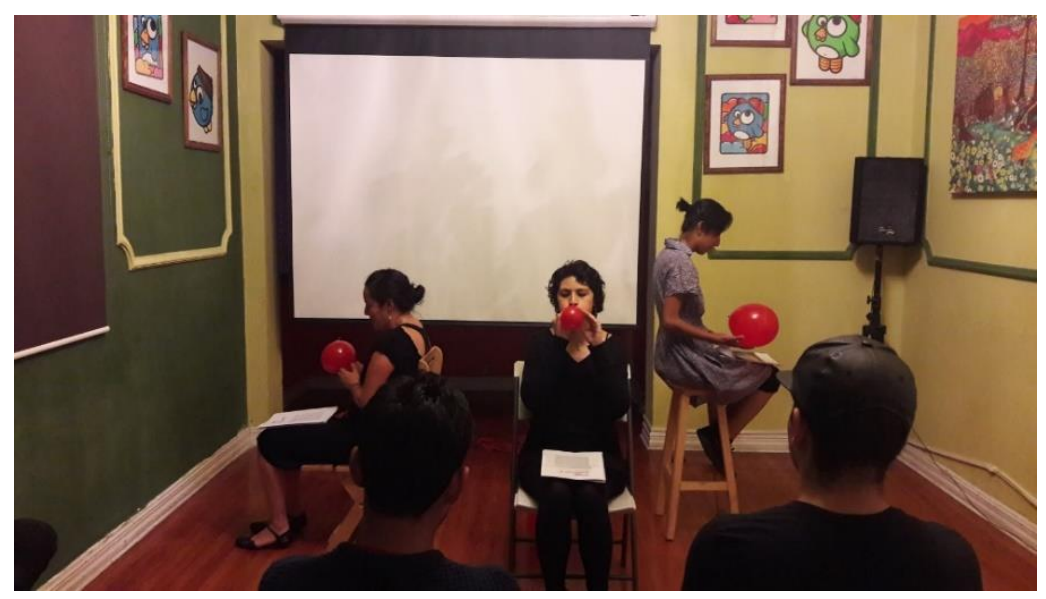

F5 y 6 Los trazos del viento en Laberinto Cultural Santa María

\footnotetext{
${ }^{8}$ Actriz y cantante. Ha tomado talleres de teatro con Ana Luisa Alfaro, Abril Pinedo y Mauricio Matus y se une a la compañía de teatro Irreverente. Formó parte del concurso Amantes del Teatro con Pedro Chuck. Forma parte de la compañía La Carnaval. Tomó un taller avanzado de Danza Teatro con Víctor Jup y Mónica Álvarez y de Doblaje de voz con Moisés Palacios. Actualmente forma parte de las compañías Marionetitlán con Gabriela Kramer.
} 


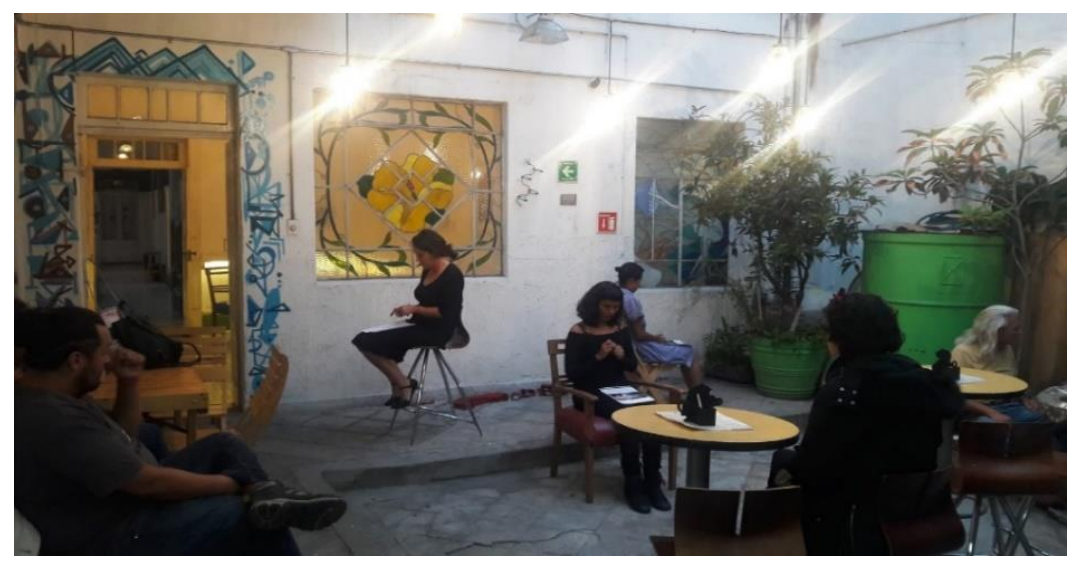

El cartel que se utilizó para la difusión de la lectura fue diseñado a partir de un elemento fotográfico en blanco y negro, en éste se encontraban zapatos rojos (este color fue decisivo para la puesta) y una cruz en el título que representa la muerte y los asesinatos.
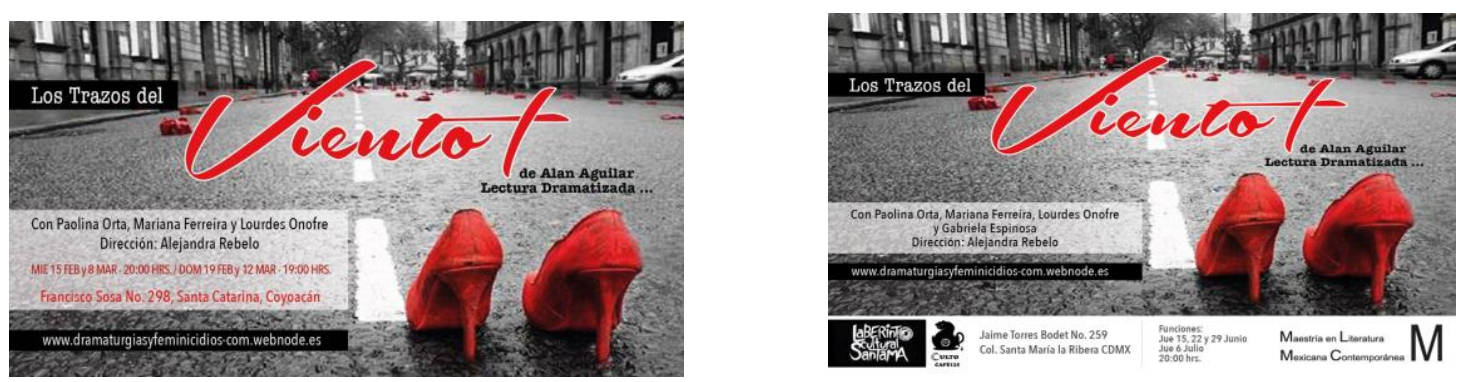

Una de las actividades del proyecto de difusión que integraba a Los trazos del viento fue una entrevista al dramaturgo Alan Aguilar Murrieta, encuentro que se llevó a cabo el 3 de febrero de 2017 en la Ciudad de México. Para el autor, esta obra, escrita hace más de 20 años, tuvo origen mientras él vivía en Tijuana en la década de 1990. En la entrevista, me contó que en aquella época trabajaba en el Centro Cultural Tijuana (Cecut) y camino a casa fue testigo de historias de mujeres trabajadoras de la maquila en esta zona fronteriza. 
Entre las circunstancias que destaca Alan Aguilar durante el proceso creativo de Los trazos del viento está la cercanía con los feminicidios en Ciudad Juárez: el autor estuvo vinculado con activistas que cuestionaban la explotación de las mujeres trabajadoras de la maquiladora. Al preguntarle cómo surge Los traz̧os del viento, me comentó que tenía muy claro qué historia contar y qué rostros imaginaba mientras escribía el texto:

Quise hacer un texto de denuncia y homenaje. Lo que sí yo tenía muy claro eran esas dos cosas: 1) que quería denunciar lo que estaba pasando porque me parecía muy grave, triste y doloroso y que había que hablar de eso; 2) de homenaje por lo tanto para mí fue muy claro que los personajes tenían que ser una suerte de homenaje a las trabajadoras, a las víctimas y para nada una obra que resultara morbosa o en que en algún aspecto fuera a herir la sensibilidad de los personajes. ${ }^{9}$

A más de 20 años de los primeros registros de feminicidios en Ciudad Juárez, la violencia en México no sólo se ha incrementado, sino que los crímenes de odio van en aumento sin importar el lugar. Ya no sólo es la frontera y sus maquilas, ahora es Guerrero, Puebla, Ciudad de México y el Estado de México, entidades que han superado en cifras los feminicidios cometidos en el estado de Chihuahua. Ahora se vuelve importante no sólo hablar de las muertes de madres, hijas, esposas, sino hablar de sus vidas desde lo teatral y sensibilizar al público para que no fueran sólo cifras y evitar la naturalización de las muertes de estas mujeres, así como lo plantea Alan Aguilar en la entrevista:

Alejandra: ¿Me puedes hablar de los personajes de Los trazos del viento? ¿Cómo fue este proceso creativo?

Alan: Lo que realmente era importante era valorar a las mujeres y que también dejaran de ser un número porque en las estadísticas de feminicidios se volvieron rápidamente en un número, van no sé cuántas mujeres asesinadas, entonces yo lo que quería era a manera de denuncia, y en término de personajes darles nombre y rostro; que dejaran de ser estadísticas, números.

Alejandra: ¿Y tú cómo pensaste los personajes? ¿Cómo fueron evolucionado?

\footnotetext{
9 Entrevista a Alan Aguilar Murrieta el 3 de febrero de 2017 en la Ciudad de México. Disponible en: $<$ https://www.dramaturgiasyfeminicidios.com/entrevistas-a-dramaturgos $\geq$.
} 
Alan: Así los pensé desde un principio de la realidad que abarcan estas chicas. Quería que estuviera presente la migración, eso era algo fundamental. El otro rostro era el de la madre, porque muchas son madres que es una realidad del país, de las trabajadoras, de estas chicas que son muy jóvenes, trabajadoras y madres, y la otra era el rostro de una mujer de frontera, las otras dos que migran, pero también está la joven de frontera porque no todas las trabajadoras de las maquilas son migrantes, muchas de ellas son hijas de migrantes, pero que nacen en la frontera y aun mismo en la frontera no encuentran otra posibilidad laboral que la maquiladora.

Esta chica de 15 años, era algo que vi en Tijuana y que va en el coche esos eran rostros y diálogos que yo vi en chicas de Tijuana y Juárez, ese es el personaje de la joven de frontera. Porque para mí eran tres realidades que daban el contexto general del perfil de las trabajadoras en la maquiladora y que se volvieron víctimas de estos crímenes atroces. ${ }^{10}$

En Los Trazos del viento son los recuerdos de estas mujeres los que integran la historia. La metáfora del viento es una alusión a los sueños rotos, es la muerte, aquél es el único referente al exterior y anuncia el desenlace trágico en un espacio íntimo. El viento es la nostalgia del pasado, el hastío del presente y un futuro que no llegará.

"Lomas de Poleo. Morir con alas plegadas" (2002), de Edeberto "Pilo" Galindo

Para abril de 2017, estábamos en la preparación de la próxima lectura dramatizada: La ciudad de las moscas de Virginia Hernández. Esta obra daría continuidad al ciclo de lecturas, sin embargo, esta propuesta no pudo concretarse debido a que no reunimos a los actores necesarios para dar marcha a esta segunda puesta en escena. Con el tiempo, pensé en la posibilidad de cambiar el texto para animar a los nuevos integrantes de Dramaturgias y Feminicidios como una

\footnotetext{
${ }^{10}$ Idem.
} 
buena estrategia. Los nuevos integrantes fueron Anthonio Mothe, ${ }^{11}$ Alejandro Rangel, ${ }^{12}$ Alejandro Samir Camarena ${ }^{13}$ y Jarayn Eligio ${ }^{14}$ quienes entusiasmados se sumaron al proyecto; en ese momento habíamos conformado un equipo con toda la disposición para dar continuidad a las lecturas dramatizadas.

En la cronología inicial había considerado Lomas de Poleo de Pilo Galindo como la lectura con la que cerraríamos el proyecto, pues la consideraba como la más compleja de analizar y, por consecuencia, su montaje demandaría un equipo mucho más amplio. No obstante, con la experiencia de Los trazos del viento, pensé que Dramaturgias y Feminicidios necesitaba continuar con un texto complejo que representara un reto para todos los integrantes.

11 Actor. Comenzó su carrera de arte dramático en 2010 en el Centro Cultural Roldán Sandoval trabajo profesionalmente después de ser egresado. Desde entonces, ha participado en diferentes compañías de teatro como Crearte "La magia del teatro", Onirománticos Teatro, Suo Tempore Producciones, La Bruja Comunicación escénica.

12 Actor. Miembro de la compañía de teatro independiente Irreverente a cargo de Mauricio Matus Cortés. En 20002002 fue ganador del premio como mejor actor en el Festival Universitario de Teatro por su participación en la obra Edipo imaginario. En 2001 fue miembro de la compañía de títeres Tinglado a cargo de Pablo Cueto. En 2005 fue miembro del ensamble Pajazzista. En el lapso de 2007-2009, participó en el taller de actuación impartido por Germán Jaramillo en la Escuela Nacional de Arte Teatral (ENAT).

${ }^{13}$ Actor. Ha participado en festivales como Mirada libre y Fitu con las obras: Jauría, El poder de los hombres, México de rodillas y Fábrica de juguetes. Se incorporó a las compañías CB e Irreverente dirigida por Mauricio Matus. Entre los talleres que ha tomado destacan Teatro para principiantes con Susana Azcue, Teatro y danza con Víctor Jump, Manipulación e interpretación de títeres con Javito Náhuatl y Doblaje de voz con Moisés Palacios. Actualmente forma parte de la compañía Marionetitlán con el montaje Peer Gynt.

14 Actriz y titiritera egresada de la Licenciatura en Literatura Dramática y Teatro de la UNAM. Actriz en Las cosas simples de Héctor Mendoza bajo la dirección de Gonzalo Correa por la conmemoración a los 140 años de la ENP (2008). En 2012 fue actriz y coach de niños actores con la asistencia de Margarita Mandoki para la obra El niño que no existía. En ese mismo año perteneció al Departamento de Radio del Universum en el área de producción. En 2013 perteneció a la Compañía Teatral Figurat S.C. como actriz y titiritera con la dirección de Emmanuel Márquez. Actualmente forma parte del elenco en la obra de títeres El lápiz de Sebastián de José Jorge Marín e imparte el Taller de Teatro a niños de escuela primaria en el programa Saludarte de la SEP. 
La historia de Lomas de Poleo surge del hallazgo de cadáveres de mujeres en 1996 en esta zona desértica en Ciudad Juárez, Chihuahua. Territorio yermo, Lomas de Poleo colinda con El Paso, Texas, EU; la zona la rodea casas de cartón y tiene luz improvisada, misma que los vecinos se robaban por medio de cables de los arneses hurtados de las maquiladoras.

Para Edeberto "Pilo" Galindo, la mayoría de sus textos están relacionados con el lugar donde vive: Ciudad Juárez. El también director señala que llama su atención el lado oculto que nadie quiere ver. En una entrevista que hice en la Universidad Autónoma de Ciudad Juárez en octubre de 2017, le pregunté cómo surge Lomas de Poleo. Me reiteró su interés por escribir acerca de lo que vive en una ciudad fronteriza como Juárez: los conflictos entre el narcotráfico; la corrupción y los feminicidios:

Estaba preocupado y dolido con el asunto de los feminicidios y dije: "quiero escribir un texto sobre este asunto" y había empezado a bosquejar una idea y así nació, pero entonces ya cuando empecé a ver cómo estaban los testimonios de las mamás de las niñas, de los familiares, empecé a trabajar eso, un par de entrevistas con algunos asesinos seriales y todo eso que me conmovió mucho y me impactó, me perturbó; de ahí nace Lomas de Poleo de la necesidad de hacer este grito. ${ }^{15}$

Lomas de Poleo. Morir con alas plegadas ${ }^{16}$ representa un limbo, un lugar desconocido en el que cuatro mujeres-niñas han llegado sin saber cómo ni cuándo. Lomas de Poleo destaca las circunstancias agonizantes de las víctimas y las familias frente a la incapacidad de las autoridades y la impunidad del Estado.

15 Entrevista a Pilo Galindo hecha el 13 de octubre de 2017 en la Universidad Autónoma de Ciudad Juárez. Disponible en $\leq$ https://www.dramaturgiasyfeminicidios.com/entrevistas-a-dramaturgos $>$.

${ }^{16}$ Esta obra se publicó por primera vez en 2003 en la antología Dramaturgia del Norte (Fondo Regional para la Cultura y las Artes del Noroeste), su segunda publicación fue en 2005 en la compilación de Guadalupe de la Mora titulada Cinco Dramaturgos Chibuahuenses (Gobierno Municipal de Chihuahua) y la tercera publicación se encuentra en la antología Hotel Juárez. Dramaturgia de Feminicidios de 2008 (Universidad Juárez del Estado de Durango). De esta última edición fue que se tomó el texto para trabajar en la lectura dramatizada. 
La casa en donde se encuentran las protagonistas es un umbral en el que la rutina y monotonía se intensifica en una continua pérdida de memoria. El uso de maquillaje como metáfora para cubrir los rastros de los golpes, así como el desdoblamiento de los personajes, hacen de Lomas de Poleo un texto cuyos signos y símbolos no se vinculan a ningún significado estable, pues cada cuadro adquiere una atmósfera más sombría. La casa es un refugio para Maty, Nancy, Érika y Angélica es un lugar ajeno en el que comparten recuerdos, es un cosmos en donde el tiempo y el espacio desaparecen.

En el caso del trabajo de preparación para la lectura dramatizada, el trabajo con los actores fue muy complejo, pues la obra puede presentar varias interpretaciones a partir de las víctimas, victimarios, deudos y autoridades. Así que el trabajo de mesa con los actores fue mucho más cuidadoso al hacer análisis de personajes, pues la carga simbólica y emotiva de cada uno tenía que ser muy precisa para no hacer un tremendismo o un melodrama de la puesta en escena.

Uno de los retos a los que me enfrenté como directora, fue encontrar el tono correcto para que los actores hicieran la lectura debido a que el trabajo actoral demandaba jornadas de más de cinco horas de ensayo por cada sesión. La selección de los personajes quedó de la siguiente manera:

Alejandro Rangel: Guicho/Médico 1/Jefe/Fiscal/Enfermero 1.

Antonio Mothe/

Samir Camarena: Mauro/Médico 2/Padre/Subprocurador/Enfermero 2.

Paolina Orta: Maty/Míriam.

Lourdes Onofre: Nancy/Adriana.

Mariana Ferreira/

Jarayn Eligio: Erika/Silvia.

Gabriela Espinosa: Angélica. 

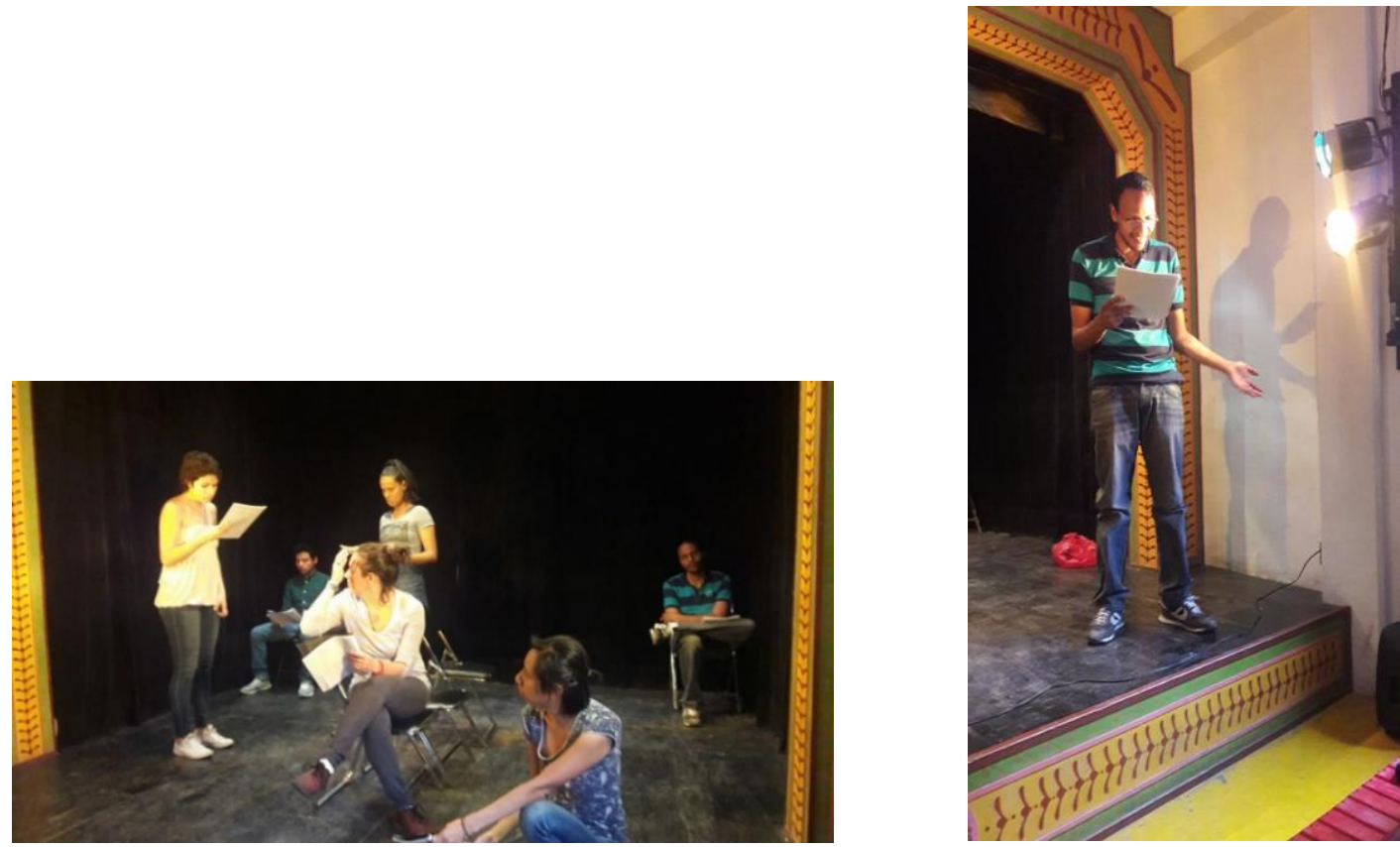

F8 y F9 Ensayo de Lomas de Poleo

El estreno de Lomas de Poleo fue el 28 de mayo de 2017 en el Teatro Lola Cuetoe y se sumaron cuatro funciones más los 4, 11, 18 y 25 de junio. Al igual que en Los trazos del viento, elegimos un vestuario neutro para todos los actores, mientras que algunos de los elementos de utilería fueron rojos para enfatizar los golpes en el cuerpo de las protagonistas.

Debido a la cantidad de personajes, todos los actores interpretaron a más de uno, así que los elementos utilizados para distinguir el cambio de rol en los cuadros fueron sombreros, cubrebocas, sacos y gorras para poder identificar al personaje que interpretaban en escena. La iluminación también fue parte importante para crear atmósferas pertinentes en la lectura dramatizada, por esto se utilizaron colores fríos para los espacios abiertos y ámbar para los espacios cerrados como la casa. 

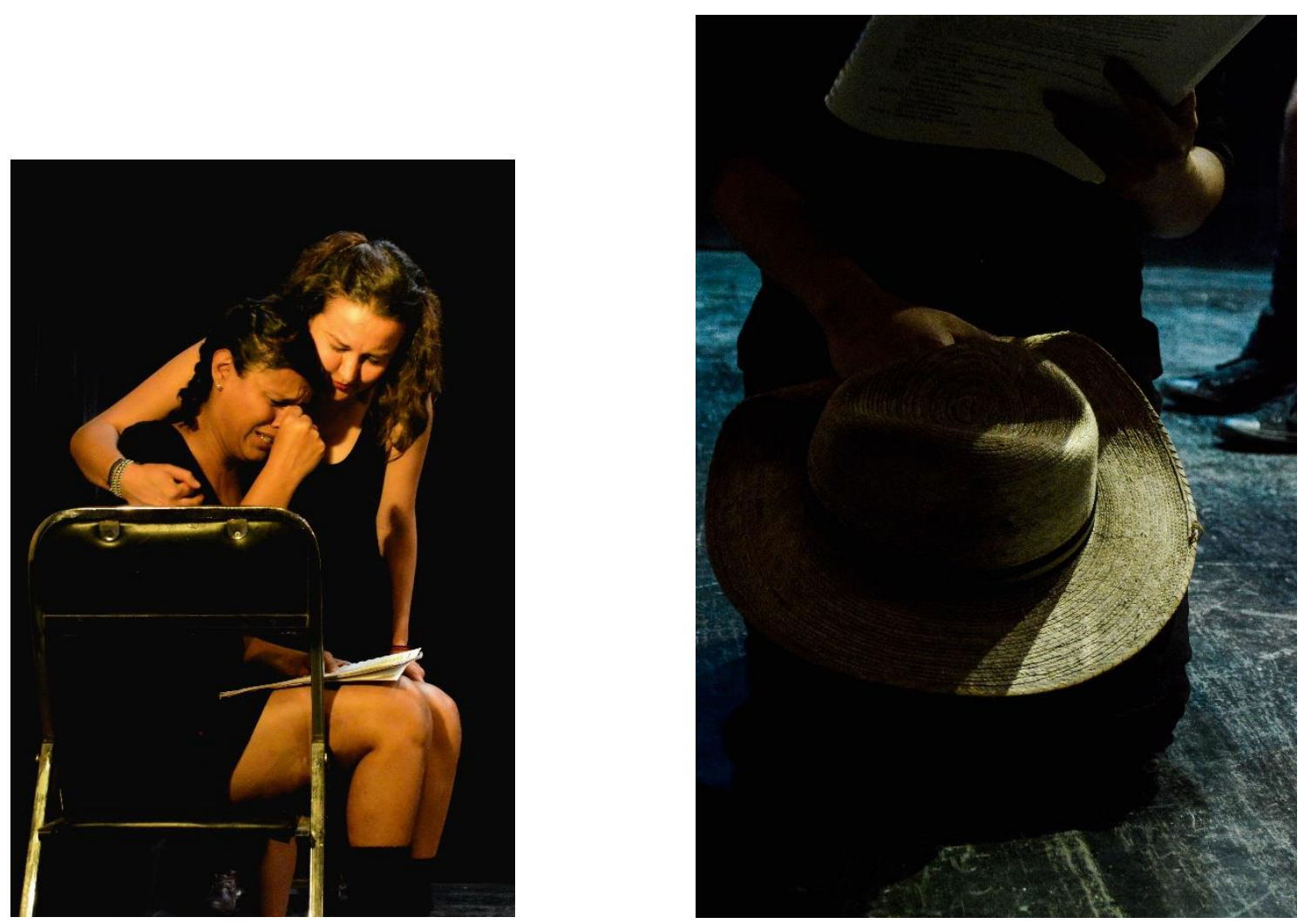

\section{F10 y F11 Lomas de Poleo en el Teatro Lola Cueto}

Con respecto de la escenografía, utilizamos tres sillas iguales en el escenario para que los cambios de cuadros se identificaran al cambiarse el asiento y así representar el ministerio público, el anfiteatro, la casa, la maquiladora y el puente. Otro de los elementos importantes para lograr momentos de tensión dentro de la lectura dramatizada fue la música; las pistas utilizadas fueron "Armenia" de Einstürzende Neubauten para dar inicio de la lectura; "Veta" de Lucrecia Dalt para trabajo en la maquiladora; "Esotro" de Lucrecia Dalt para el monólogo de Güicho; y "Vapor Barato" de Gal Costa como leitmotiv al final de cada lectura, como se mencionó con anterioridad. 


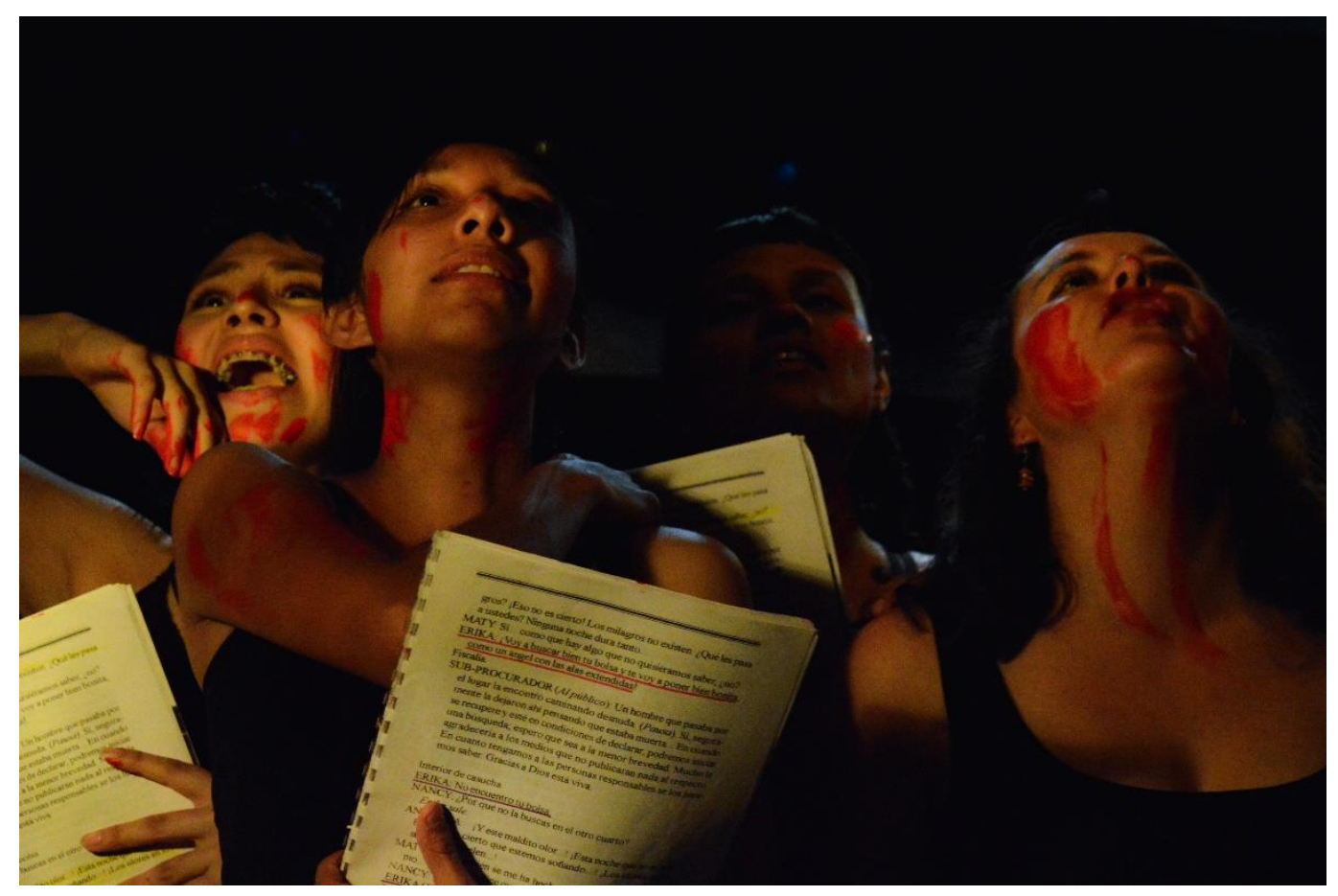

F12 Lomas de Poleo en el Teatro Lola Cueto

La recepción que tuvimos por parte del público fue interesante ya que, al terminar la obra, la mayoría de los asistentes no sabían si aplaudir pues el impacto para algunos fue tal que no sabían cómo reaccionar ante lo presenciado. En este momento nos percatamos de que ahí estaba el sentido del proyecto: sensibilizar a los espectadores por medio del teatro.

El 11 de julio tuvimos la oportunidad de presentarnos en la Universidad Autónoma Metropolitana Azcapotzalco. En un inicio se había acordado de que la función sería en el auditorio Incalli Ixcahuicopa; sin embargo, ese día tuvimos un inconveniente para presentarnos en ese recinto, pues no estaba disponible a pesar de haberlo solicitado con semanas de anticipación. A pesar de la insistencia por parte del coordinador de la Maestría para que se respetará el espacio, no pudimos presentarnos en el auditorio, pues aparentemente nadie contaba con las llaves para poder ingresar. 
Se pensó cancelar la función después de dos horas de espera, pero pensamos en los lugares que podíamos presentarla, mas no podíamos ni queríamos dejar la oportunidad de presentarnos en la UAMA: pues queríamos aprovechar la invitación hecha a profesores y a alumnos. Después de sortear todos los inconvenientes dentro de la unidad, tuvimos la fortuna de presentarnos en el auditorio K-001 gracias a la insistencia y apoyo del Dr. Christian Sperling y la Lic. Reyna Ruiz. La recepción del público fue muy buena y ante un foro lleno, intercambiamos comentarios con algunos profesores y alumnos presentes.
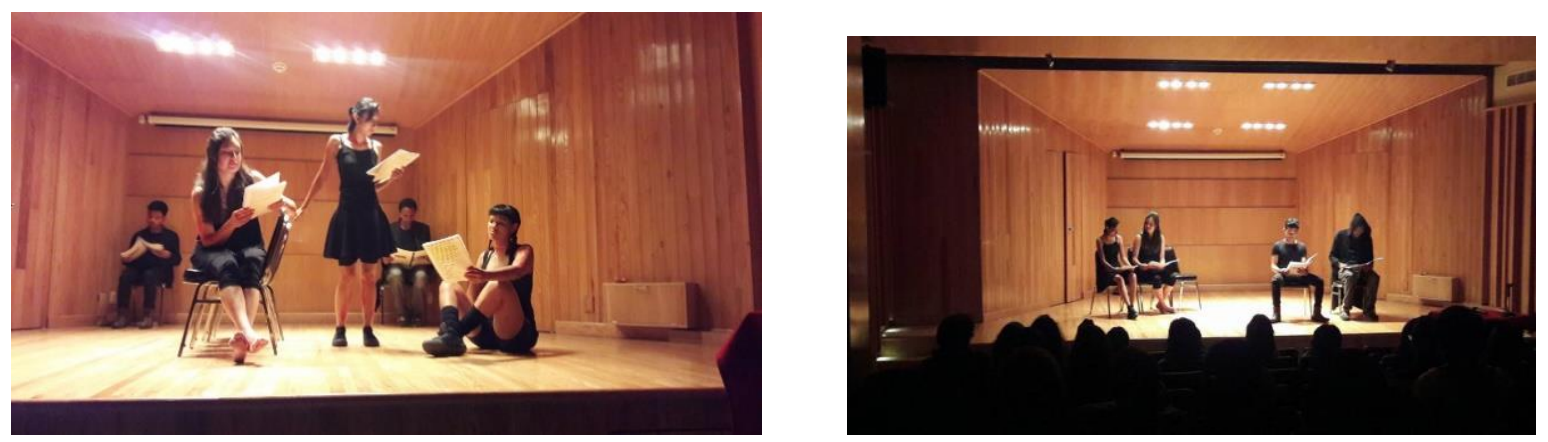

F13 y F14 Lomas de Poleo en UAM Azcapotzalco

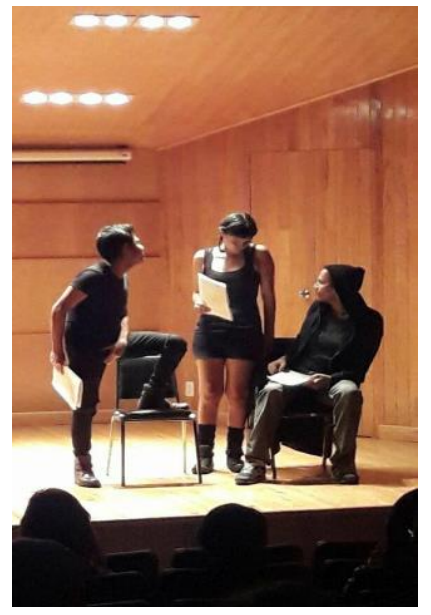

F15 Lomas de Poleo en UAMAzcapotzalco 
Al término de cada función, pedimos la opinión de los asistentes: pensamos que los comentarios por parte del público podían ayudarnos a mejorar la logística o el trabajo actoral de las lecturas.

Aquí algunos de los comentarios después de las funciones:

Les agradecemos sus comentarios al equipo de Dramaturgias y Feminicidios:

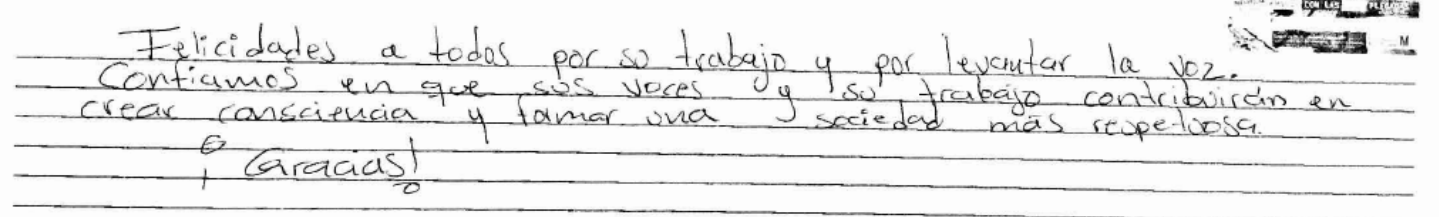

Si desean recibir información de próximos eventos de Dramaturgias y Feminicidios les solicitamos su correo electrónico amaranta.arrache@hotmail.ıom

MUCHAS GRACIAS.

F16 Comentarios sobre Lomas de Poleo

Les agradecemos sus comentarios al equipo de Dramaturgias y Feminicidios:

iHula:

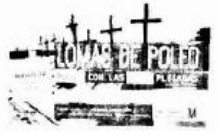

Yo quere felicitar as todes. Se ha transtomacts muchu bu actucaun y todu la funcion. les flicito mucho.

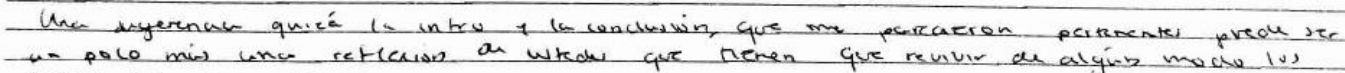

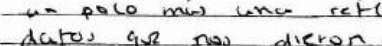

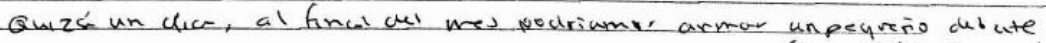

Si desean recibir información de próximos eventos de Dramaturgias y Feminicidios les solicitamos su correo electrónico con wirechs pura- Jube-. K

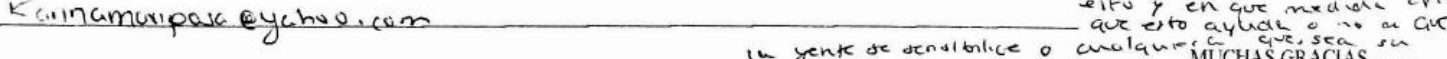

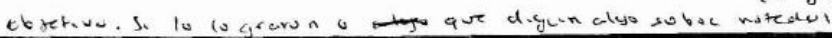



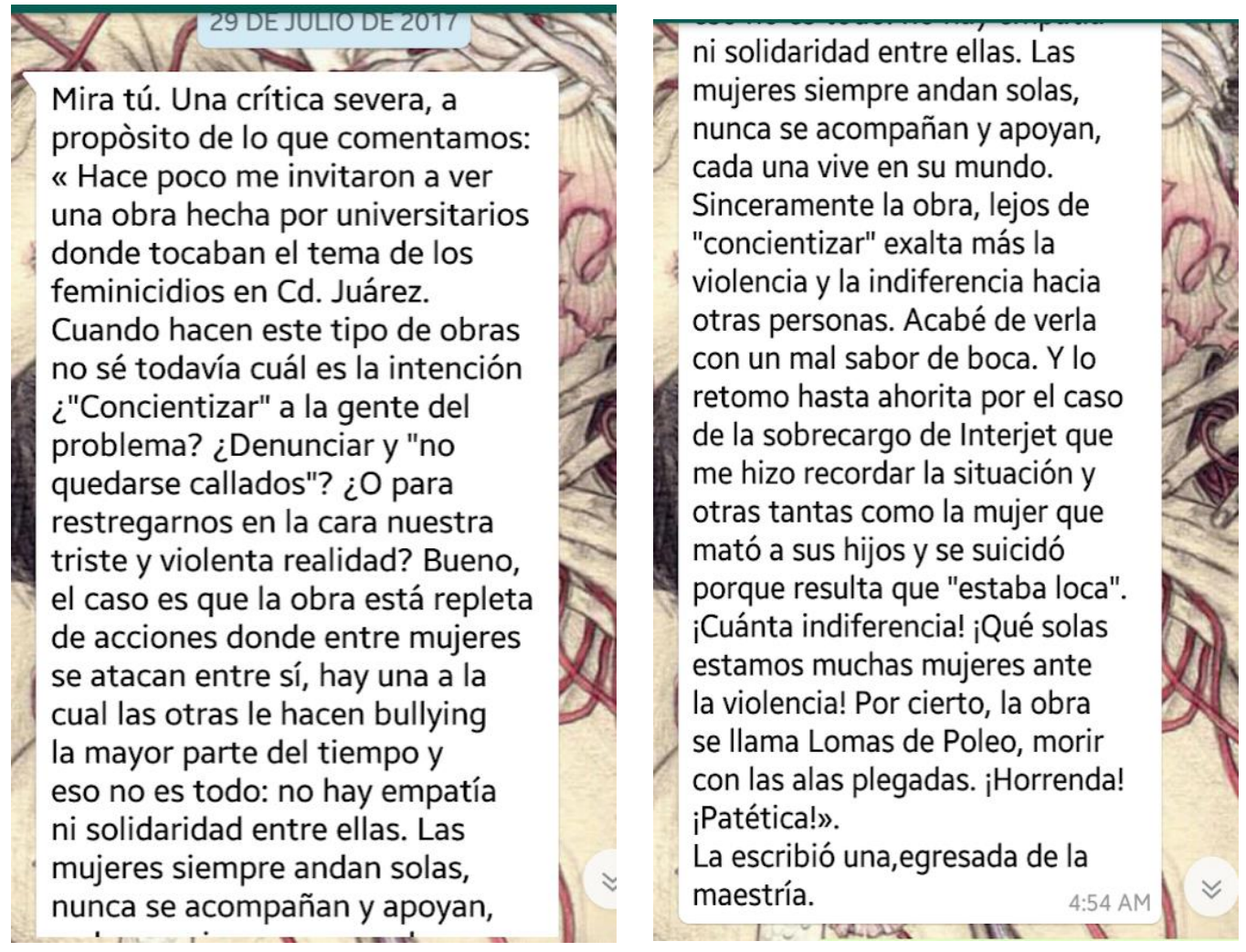

F18 y F19 Comentarios sobre Lomas de Poleo

Esta última crítica la recibí por WhatsApp y fue de un profesor; me pareció interesante la opinión, pues en el quehacer teatral bien las interpretaciones por parte de los espectadores pueden ser diversas, así que consideré pertinente incluirla porque todas las voces son válidas.

Con esta presentación en UAMA dimos por terminada la segunda lectura dramatizada de Dramaturgias y Feminicidios. Al igual que Los trazos del viento, con Lomas de Poleo tuve la oportunidad de entrevistarme con el dramaturgo Pilo Galindo, me pareció importante dialogar con el autor respecto a su obra, conocer su opinión acerca de la violencia de género que se vive en nuestro país y la censura que tuvo esta obra para su publicación:

Alejandra: ¿Qué importancia tiene el contexto en su obra dramatúrgica? 
Pilo: Pues, yo creo que tiene un sentido hasta a veces casi antropológico, hablo mucho de lo que sucede aquí en Juárez, de lo que nos pasa. He estado recurriendo últimamente a la Historia, cómo nacimos nosotros, qué paso cuando llegó aquí Pánfilo Narváez y Cabeza de Vaca. ¿Qué éramos nosotros aquí? He empezado a recorrer esa parte de la Historia, pero yo escribo básicamente de la vida, los días, lo que pasa día a día es la materia prima para cada escritor, no solamente para un dramaturgo y, bueno, yo vivo en Juárez y hablo de lo que nos pasa acá.

Alejandra: Y hablando de lo que pasa acá: ¿cómo surge Lomas de Poleo?

Pilo: Bueno, yo estaba en una situación económica bastante difícil y me fui a Estados Unidos, pero antes de eso hubo un foro aquí en el que estuvimos Joaquín Cosío y yo en el museo del INBA (ahora se llama Museo de Arte), y yo les dije que estaba preocupado y dolido con el asunto de los feminicidios y dije: "quiero escribir un texto sobre este asunto", y había empezado a bosquejar una idea. Así nació, pero, entonces, ya cuando empecé a ver cómo estaban los testimonios de las mamás de las niñas, de los familiares, empecé a trabajar eso, un par de entrevistas con algunos asesinos seriales y todo eso que me conmovió mucho y me impactó, me perturbó. de ahí nace Lomas de Poleo de la necesidad de hacer este grito.

Alejandra: ¿Y el proceso de los personajes?, ¿cómo surgen? ¿Cómo fueron evolucionando?

Pilo: Pude haber hecho una obra tremendista, una obra hiperrealista, pero yo recurrí a esta figura literaria casi poética de las chicas hablando del maquillaje, esperando la luz del día como la esperanza y yo creo que esos personajes son niñas y están en un limbo y no saben dónde están, no saben qué va a pasar y no quise cometer otra atrocidad en el teatro con ellas y por eso usamos estas figuras literarias y cree estos personajes dolientes, sufridos, pero con esperanza.

Alejandra: ¿A qué se refiere con el limbo en el que están estas niñas?

Pilo: Es una especie de embriaguez, de confusión, no saben dónde están, no saben qué paso, cuando al final lo descubren tienen una actitud valiente las chicas, y sobre todo Érika, Matilde es muy solidaria con Nancy, que era una niña y no sabían que eran una niña.

Alejandra: ¿Alguna vez han censurado alguno de sus textos?

Pilo: Loma de Poleo fue la obra que ganó el premio en Chihuahua. Cada vez que un dramaturgo, un escritor, gana un premio en Chihuahua de Literatura le publican inmediatamente su obra, le entregan su premio y su libro publicado, excepto Lomas de Poleo.

Alejandra: ¿Y le dieron alguna razón?

Pilo: No te puedo decir. Bueno te voy a decir textualmente lo que me dijeron: "No publicamos esa clase de basura". ¿Sí me explico? O sea, les pegaba el tema y me acuerdo que yo monté a gritos y a sombrerazos Lomas de Poleo aquí en Juárez y dije: "bueno, no me van a prestar el teatro, lo voy a montar aquí en la calle". Estábamos batallando mucho con el teatro y llegó Manuel y nos echó la mano y finalmente la montamos en el auditorio Benito Juárez y nos cobraron 
un ojo de la cara y la mitad del otro por la renta del teatro, o sea la idea era que no la montáramos, pero afortunadamente el teatro estaba a reventar, se llenó.

Por último, el diseño del cartel que se utilizó para promocionar Lomas de poleo fue la imagen de un paisaje desértico en alto contraste para aludir el lugar en donde se encontraron los cuerpos de las mujeres, las cruces como símbolo de muerte y el color rojo en las palabras MORIR y ALAS.

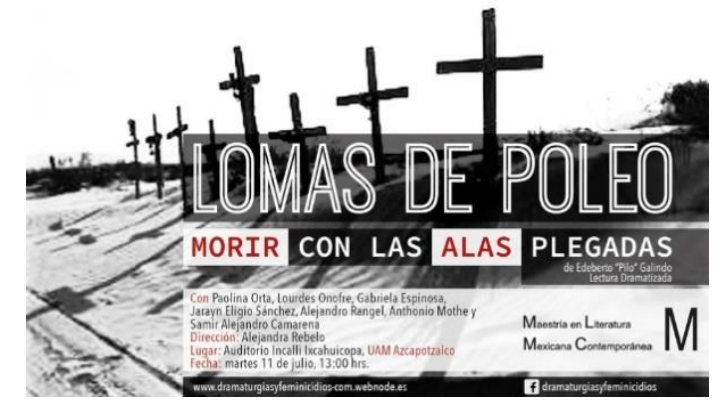

F20 Cartel de Lomas de Poleo en el Teatro "Lola Cueto"

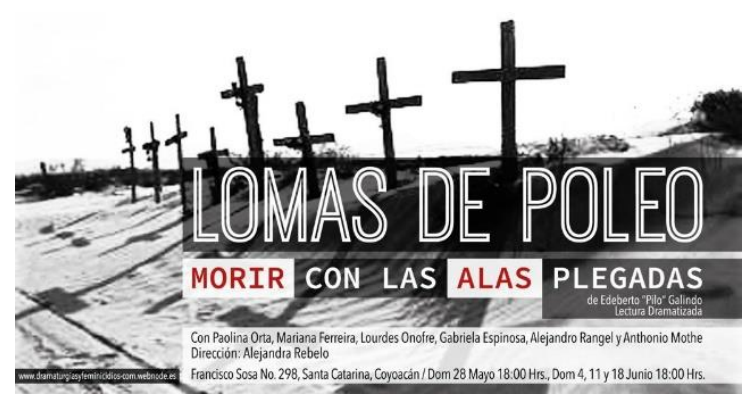

F21 Cartel de Lomas de Poleo en UAMAzcapotzalco

"Sirenas de Río" (2007), de Demetrio Ávila

Para septiembre de 2017, nos reunimos para dar continuidad a las lecturas dramatizadas. El equipo de actores de nuevo tuvo algunos cambios para el final del proyecto, pues originalmente el estreno estaba contemplado para octubre, sin embargo, a una semana de la primera función, uno de los actores tuvo que renunciar al proyecto y por esta razón buscamos quién pudiera sustituirlo. Entre ensayos cancelados y elenco incompleto, tuvimos que postergar un mes el estreno para poder conformar el elenco final de Sirenas de Río de Demetrio Ávila; al final, lo 
conformó: Paolina Orta, Gabriela Espinosa, Jarayn Eligio, Samir Camarena y Roberto Feregrino. $^{17}$

Uno de los criterios, para seleccionar Sirenas de Río como el último texto en el corpus de lecturas dramatizadas, fue la experiencia previa con Lomas de Poleo, pues esperábamos continuar con un texto de impacto similar al anterior, debido a esto, los actores y yo acordamos que Sirenas de Río sería un buen texto porque el escenario teatral trae de regreso las historias de mujeres que perdieron identidad en un río, no son sirenas que seducen, son sirenas víctimas de una violencia y sus perpetradores arrojaron sus restos para borrar los rastros de los crímenes.

¿Cómo definir un texto tan complejo como Sirenas de Río? En esta obra, un río es cómplice y verdugo en historias que coinciden con la muerte de madres, hijas, trabajadoras y prostitutas. Las voces de las sirenas emergen de la profundidad de un río de sangre en la frontera. Los acontecimientos de esta obra suceden en el espacio público. El río es una figura omnipotente y omnipresente alrededor de los personajes: es una representación del machismo. El río alberga en su profundidad a mujeres asesinadas que se transforman en sirenas en el momento de su muerte. Las narrativas se estructuran a partir de los siguientes ejes dramáticos:

A partir de un hombre que abusa de una niña.

Una maestra que denuncia el acoso de un hombre en una escuela.

\footnotetext{
17 Licenciado en Letras Hispánicas por la Universidad Autónoma Metropolitana Iztapalapa y Especialista en Literatura Mexicana Siglo XX por la Universidad Autónoma Metropolitana Azcapotzalco. Participó como Director Editorial en la revista R-imagina-T en el 2006. En el 2007 ganó el concurso de ensayo Juan Rulfo que promueve la Universidad de Aguascalientes con el trabajo "Susana San Juan y Pedro Páramo como dos elementos de la naturaleza". Promotor en 2008 del Centro Documental de Casa Vecina. Espacio Cultural. Participó en la elaboración del libro junto a la curadora Jesica Berlanga Taylor Los 100 momentos más significativos del arte contemporáneo desde la ciudad de México (2012) que promovió la editorial Código. Ha hecho entrevistas para la revista digital sin embargo y como corrector de estilo para la revista Forbes México.
} 
Una madre que pierde a su hija, padre e hijo que comparten el asesinato como pasatiempo.

Mujeres agredidas en su domicilio.

Una prostituta asesinada por un joven.

Una anciana indiferente hacia los asesinatos y las trabajadoras de una maquiladora.

Son historias que se entrelazan, fragmentos que comparten en un espacio mancillado por el río en sus múltiples representaciones.

Los personajes de Sirenas de Río representan a la sociedad (joven 1, 2, doctor, enfermera, anciana); los deudos (madre, señora, mamá de Grettel): el río (hombre, padre, hijo, hondureño, joven); y las víctimas (niña sirena, Grettel, obrera 1, Carmen, Isabel, prostituta). La violencia se genera en cada escena y está presente en varias situaciones: en la descomposición social, en el abuso, en la injusticia, en la corrupción, en el miedo y, por supuesto, la indiferencia.

Para Demetrio Ávila, la violencia se manifiesta en las calles, en la humedad. Los personajes de Sirenas de Río surgen en una primera propuesta como una coreografía de danza contemporánea de Rolando Beattie, pero estas mujeres no sólo querían danzar, "necesitaban voz, denuncia", relata el dramaturgo tampiqueño en entrevista:

Recuerdo muy bien la primera imagen. Había platicado con uno de los coreógrafos más importantes del país, quería que hiciera la dramaturgia de su nueva coreografía, me había contado una primera idea, de un río rojo. Él debió ver mi cara de terror y me dijo: "salga a caminar, nos vemos después de la comida; a ver qué tiene". Salí a caminar; en las calles había más camiones de soldados y patrullas que gente, la violencia empezaba a meterse como la humedad en nuestras tierras y supe bien de qué quería hablar. ${ }^{18}$

\footnotetext{
${ }^{18}$ Demetrio Ávila cuenta como anécdota que la edición de la antología Hotel Juárez ya estaba cerrada y en revisión, sim embargo, Enrique Mijares, que era el editor, decide integrarla a los 10 textos ya seleccionados, así que Sirenas de Río fue la 11 de una antología que estaba a punto de ser publicada.
} 
Demetrio Ávila escribío Sirenas de Río en un taller de dramaturgia en Reynosa, Tamaulipas, con ello dejó la propuesta dancística para dar origen a un texto dramático con la supervisión de Enrique Mijares. Las historias de estas mujeres-niñas son desgarradoras porque la violencia está implícita en sus gestos y en sus recuerdos y la esperanza por ser encontradas por su familia.

Al igual que con Lomas de Poleo, el trabajo de mesa con los actores fue muy cuidadoso, pues no queríamos hacer una representación tremendista del texto. Si bien, Sirenas de Río representó un reto por la falta de continuidad del elenco, pero dedicamos varios ensayos para hacer un análisis de los personajes, pues en esta ocasión todos los actores tuvieron que interpretar hasta cuatro personajes debido a la brevedad y la complejidad de cada una de las escenas: demandaba un trabajo mucho más preciso.
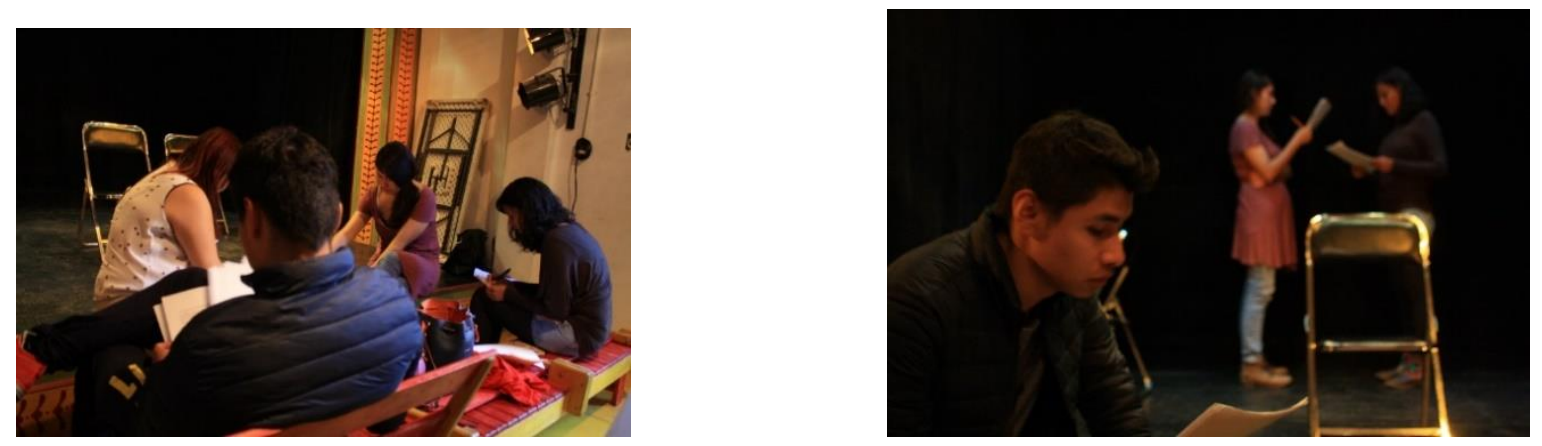

F22 y F23 Ensayo de Sirenas de Río

El elenco se integró de la siguiente manera:

Roberto Feregrino: Río/Padre/Joven.

Paolina Orta: Joven 1/Carmen/Prostituta/Anciana/Obrera 1.

Jarayn Eligio: Maestra/Mamá de Grettel/Isabel/Madre.

Gabriela Espinosa: Niña sirena/Joven 2/Grettel/ Enfermera/Obrera 2.

Samir Camarena: Hombre/Hijo/Doctor. 

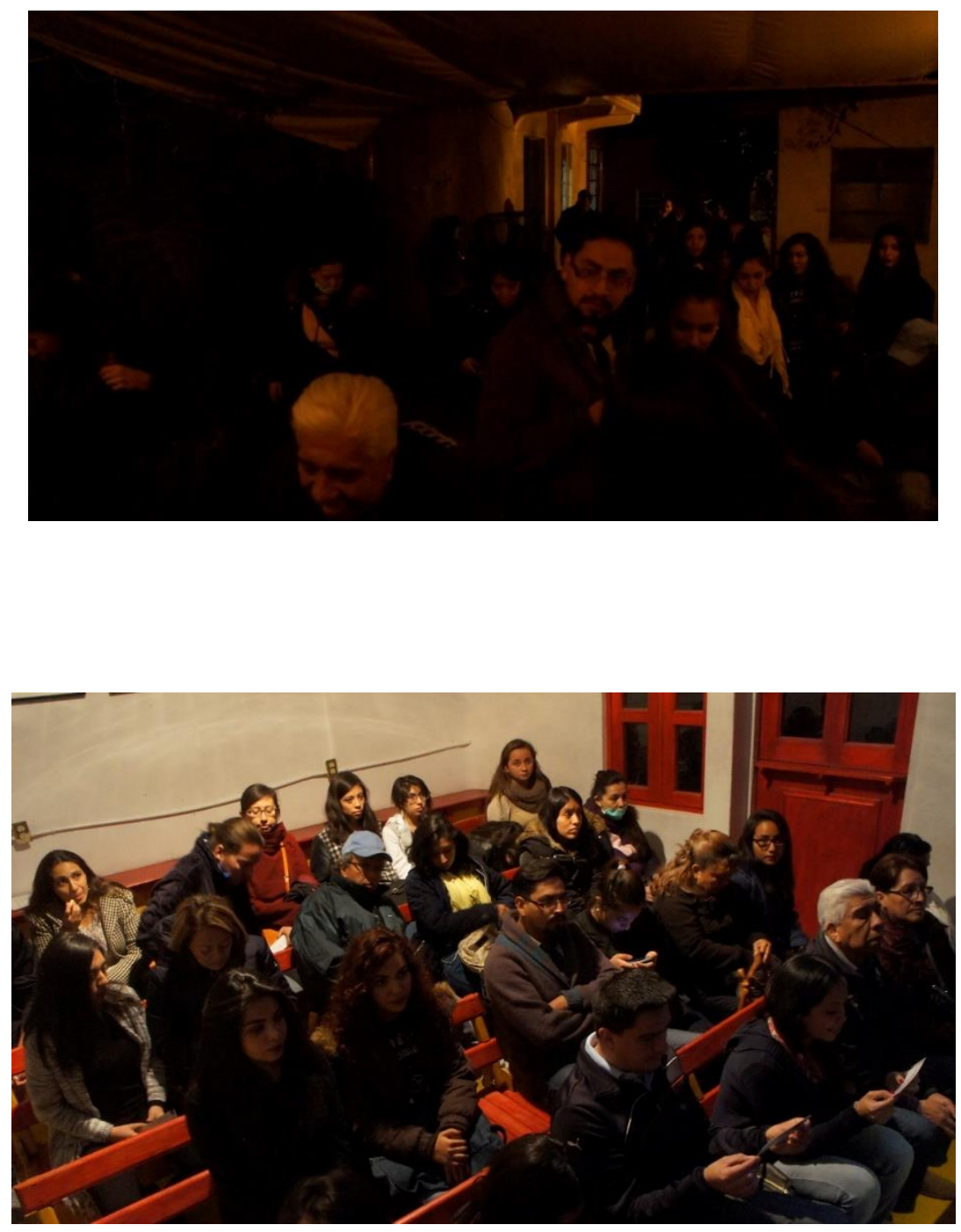

F24 y F25 El público de Sirenas de Río

El vestuario, al igual que en las otras dos lecturas, fue neutro, pues los cambios de tonos para marcar el cambio de personajes se hacía por medio de la alternación del color de luces: Ccuando en escena se encontraban las sirenas, se utilizaron colores fríos y ámbar para la entrada de personajes masculinos.

Respecto a la escenografía, en esa ocasión sólo utilizamos dos sillas que ayudaban a marcar los cambios de escena y de personajes. Otro elemento que consideramos importante en la puesta 
fue el uso de lámparas en el puente de la obra, pues, en esta escena, la luz representaba el reconocimiento de los cuerpos arrojados al río, es decir, una naturalización de los hechos.
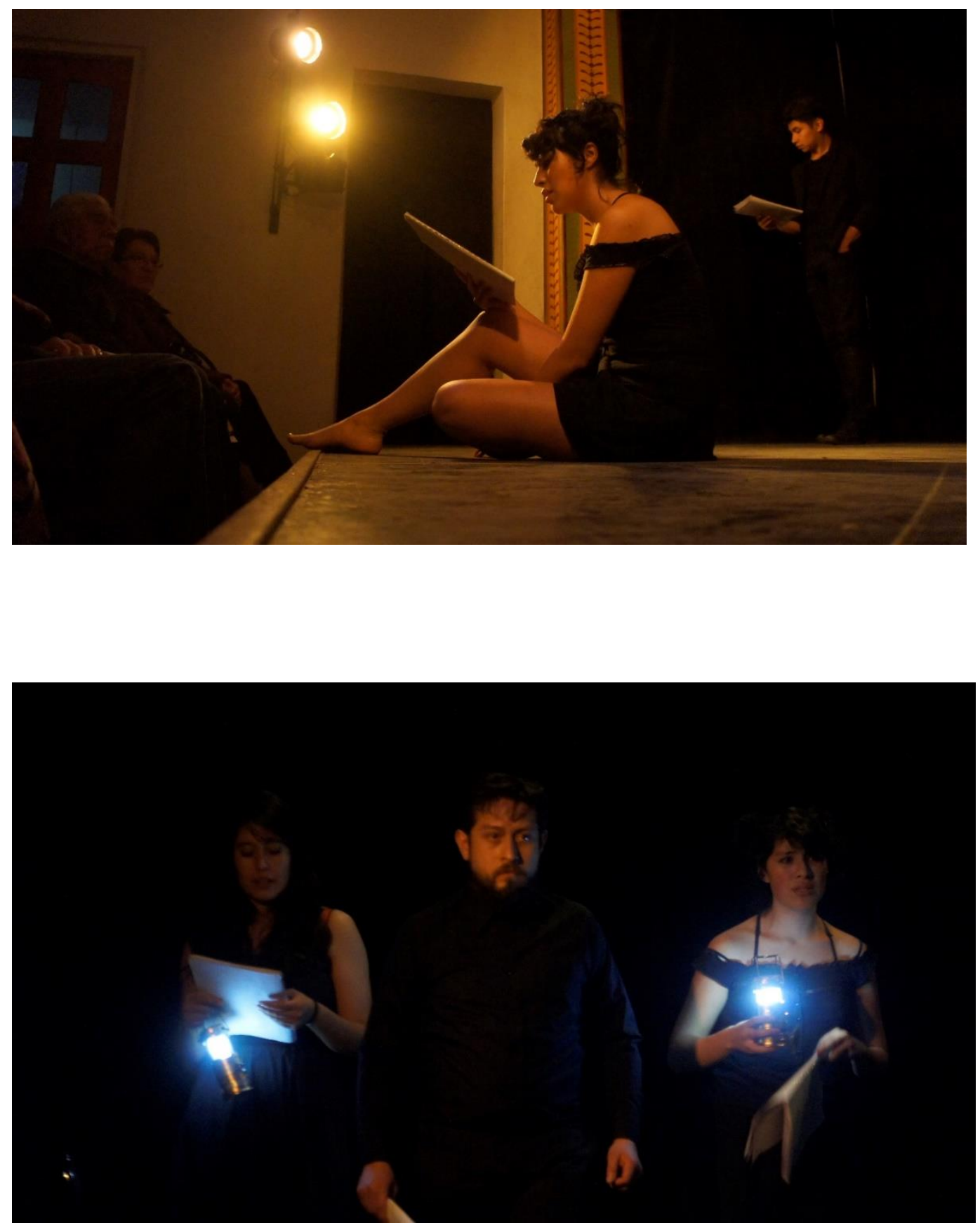

F26 y F27 Sirenas de Río en el Teatro Lola Cueto

La música seleccionada para crear los ambientes en Sirenas de Río fue: "Mirage" de Lucrecia Dalt para el puente y el juego de las actrices con las lámparas; "Para todas las mamitas del 
mundo" de Paloma Cerro para entrada de público; y "Vapor Barato" de Gal Costa al final de la lectura como leitmotiv.

Por fortuna, tuvimos una muy buena recepción por parte del público, por lo mismo, aprovechamos la dinámica de pedir la opinión de los asistentes como en Lomas de Poleo para poder mejorar en próximas presentaciones; algunos de los comentarios:
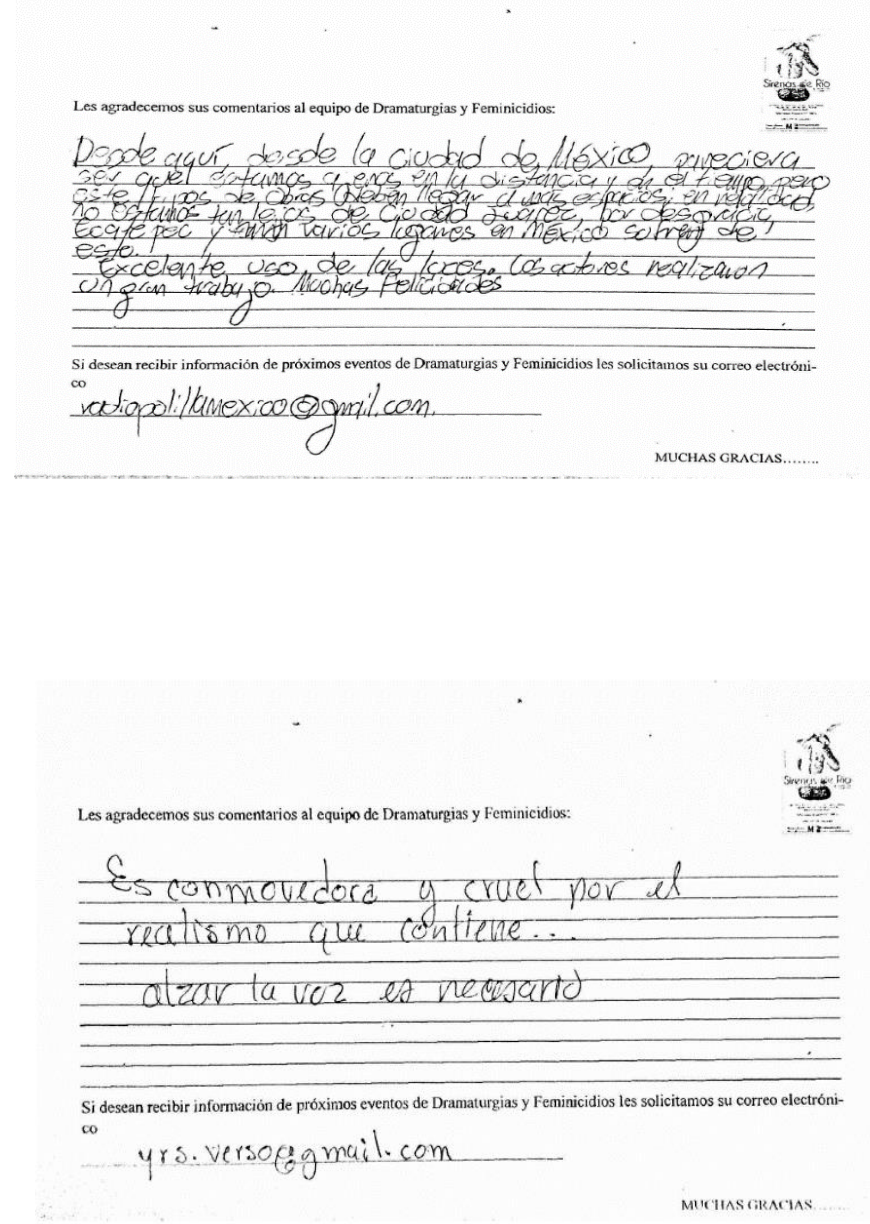

F28 y F29 Comentarios Sirenas de Río

El miércoles 22 de noviembre tuvimos la oportunidad de presentarnos de nuevo en UAM Azcapotzalco, pero con Sirenas de Rio. El lugar fue el auditorio K-OO1, (mismo espacio para la 
presentación de Lomas de Poleo), sin embargo, no tuvimos la respuesta que esperábamos porque a las 15 horas muchos alumnos ya no se encuentran en la unidad.

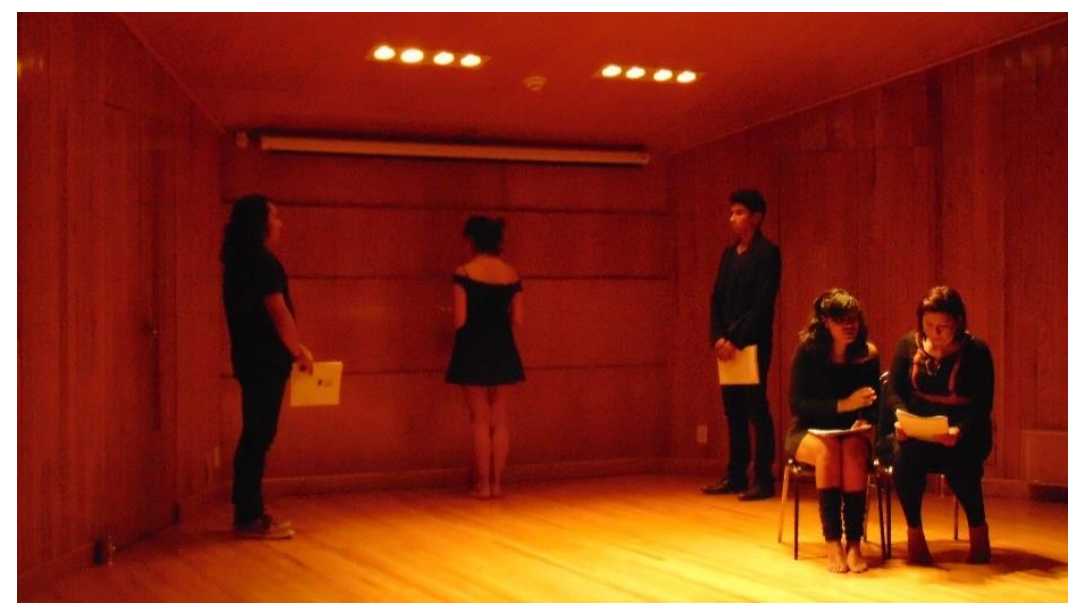

F30 Sirenas de Río en UAMAzcapotzalco

En Sirenas de Río, el río es la representación de la corrupción y de la indiferencia. Las mujeres que han sido violadas, mutiladas y asesinadas son arrojadas al río como un trofeo para los victimarios. El río se convierte en una tumba, en un espacio en donde no importa quiénes eran esas mujeres que han sido violentadas; la falta de identidad, el exceso de dolor y violencia impera en cada una de las escenas. El río se tiñe de sangre porque las sirenas son madres, hijas, obreras, niñas o prostitutas. Para Demetrio Ávila, "son mujeres que viven bajo este río que somos todos, un sistema putrefacto, una religión que las somete y les lava el cerebro para minimizarlas y cosificarlas". ${ }^{19}$

La voz del dramaturgo es importante para contar el proceso creativo de su obra. Al iniciar los ensayos para la lectura de Sirenas de Río, me puse en contacto con Demetrio Ávila para solicitar

19 Entrevista con Demetrio Ávila hecha de manera virtual el 10 de octubre de 2017. Publicada en $\leq$ https://www.dramaturgiasyfeminicidios.com/entrevistas-a-dramaturgos $>$. 
una entrevista de manera virtual, pues el autor vive en Tampico, Tamaulipas. Me di a la tarea de buscarlo por sus redes sociales y amablemente no sólo nos permitió la lectura de su texto, sino que me otorgó una entrevista entrañable de la que comparto un fragmento:

Alejandra: ¿Qué importancia tiene el contexto en tu obra dramatúrgica?

Demetrio: La violencia llegó a mi tierra silenciosa, sin hacer mucho escándalo, como leyenda urbana. Junto a ella la descomposición social, el abuso, al principio el miedo, la indiferencia después [...] Acá hombres y mujeres hemos aprendido a susurrar en los restaurantes porque no sabemos quién come junto a nosotros, hemos bajado la velocidad en nuestros coches y rebasamos poco, olvidamos el claxon, el miedo nos ha devuelto la cortesía, pero hemos aprendido a regar las plantas mientras en la esquina de nuestra casa se desata una balacera infernal en el penal del estado. No somos los mismos: nos deben una generación que encuentra más divertido un juego de sicarios y policías que de canicas y "encantados". De eso quiero hablar porque no quiero olvidar lo que fuimos y me rehuso a continuar siendo lo que veo.

\section{Alejandra: ¿Cómo surge Sirenas de Río?}

Demetrio: Recuerdo muy bien la primera imagen, había platicado con uno de los coreógrafos más importantes del país, quería que hiciera la dramaturgia de su nueva coreografía, me había contado una primera idea, de un río rojo. Él debió ver mi cara de terror y me dijo: "salga a caminar, nos vemos después de la comida; a ver qué tiene”. Salí a caminar; en las calles había más camiones de soldados y patrullas que gente, la violencia empezaba a meterse como la humedad en nuestras tierras y supe bien de qué quería hablar [...] Yo investigaba de casos en Tamaulipas o en el país: quería saber; entender, mejor dicho, los motivos para ejercer semejante violencia. Empecé a recordar mujeres cercanas, conocidas. Conocí el caso de la niña, que era hasta ese momento la víctima más joven y no paré de llorar al imaginar que fuera mi sobrina o que alguna de esas mujeres fueran de mi familia, empecé a ponerle rostro a las desconocidas y la historia me llegó profundo, me di cuenta que la indiferencia es también otra forma de violencia, no hablo de la ignorancia, cuando no sabes, quizás, y solo quizás, no eres tan culpable, cuando lo sabes y volteas la mirada para que no sentirte culpable o partícipe o conmovido al menos, porque el dolor también asusta, no hay pretexto. Cuando supe de esto no quise quedarme callado. Incluso mientras escribía la obra ocurrió un asesinato ahí en Reynosa, una obrera había sido ultrajada y asesinada por un hondureño que había sido deportado y lo dejaron ahí.

Alejandra: ¿Me podrías hablar de los personajes de Sirenas de Río?

Demetrio: Las mujeres que cuentan su historia son mujeres de Tamaulipas que anduvieron estas calles. Sus historias me estremecieron y por eso quise rescatarlas del olvido. Mujeres a quienes les cortaron los dedos para que no las reconocieran o les arrancaron a mordidas los pezones en un 
festín de sadismo y lujuria. Mujeres que siguen sentadas esperando a que sus hijas vuelvan. Estas sirenas son mujeres que viven bajo este río que somos todos, un sistema putrefacto, una religión que las somete y les lava el cerebro para minimizarlas, cosificarlas. La niña sirena es un personaje que tomé de la nota roja de Cd. Juárez, era hasta ese entonces la víctima más joven, metaforicé la historia y la traje a mi realidad para construir con su ficción una conciencia de la inocencia que debería permanecer intacta hasta que caiga como dientes de leche, sola, sin violentarla, sin interrumpirla. La inocencia es algo que nunca se pierde, solo se esconde, si la dejáramos salir más seguido, seguro seríamos mejores hombres y mujeres.

Las sirenas son personajes que quiero mucho porque me han dolido mucho, conocí sus historias y algo de mí hay en cada una, esa necesidad del abrazo, de entregarte de creer, de buscar el cobijo de un abrazo. A una de ellas la conocí una madrugada en Tampico al cobijo del umbral de iglesia en medio de la tormenta. Su figura me ha perseguido desde entonces; ella sólo quería un abrazo, de verdad, un huequito para guardarse, para mirar de cerca la esperanza. No murió esa noche. Juntos vimos amanecer, sentados en la banqueta, mientras el sol nos secaba la ropa. Las demás historias las conocí por amigos o por la prensa, todas con una historia de esperanza antes de su muerte, ninguna esperaba morir así y casi todas conocían a sus victimarios. ¿Cómo desconfiar cuando la muerte tiene una cara amiga, una palabra amable? ¿En qué momento los demonios surgen para teñir de rojo la sonrisa de quien yace y de quien espera su regreso en casa?

Hablar de las Sirenas de este rio rojo es hablar de las muertas de Juárez, de las muertas de Guerrero, de las de Chiapas, es hablar del cadáver de mi madre esperando que mi padre regrese del otro lado del río, es contar la historia de mi vecina que se fue un día a la maquiladora y no regresó ni porque sus hijos la esperaban a comer. Este trabajo pretende apenas recordarnos que el río rojo nos moja los pies a todos y que cada uno vamos formando pequeñas olas-brazos de río.

En este río de agua estancada se sumergen mujeres diariamente y a veces sacan su cara del agua para respirar un poco y recordarnos que aún viven y que aún esperan y que junto a su espera nosotros también estamos esperando. ${ }^{20}$

Después de conocer toda la historia detrás de Sirenas de Río, pensé en un cartel en el diseño impactante para un texto entrañable y atroz al mismo tiempo; seleccionamos una imagen que pertenece a la colección Metamorfish de la artista española Elisa Ancori. En el motivo de creación de la propaganda, pensamos en la imagen de una sirena sin mostrar el rostro como idónea para

\footnotetext{
${ }^{20}$ Ibidem.
} 
el cartel, pues era una metáfora de aquellas mujeres que han perdido identidad como se plantea en la obra, además las sirenas no son seres mitológicos en la obra, sino son víctimas de un tsunami de violencia, como señala el Dr. Antonio Marquet. Estos fueron los carteles utilizados para promocionar la lectura de Sirenas de Río:

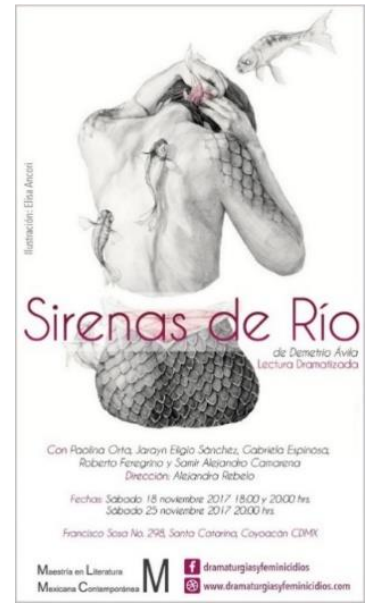

F31 Cartel de Sirenas de Río para el Teatro Lola Cueto

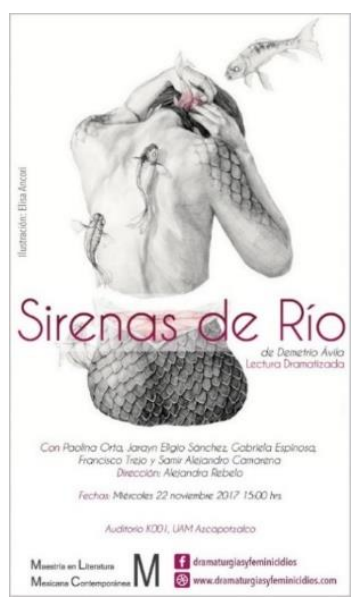

F32 Cartel de Sirenas de Río para UAM Azcapotzalco

Para finalizar con Sirenas de Río, tuvimos la fortuna de tener una reseña en la revista electrónica Sinestesia Escénica: Revista Michoacana de Estudios de la Escena Contemporánea coordinada por Said Soberanes, Ramsés Figueroa y Gunnary Prado. Amablemente Juan Fernando Hernández García escribió un texto a propósito de la lectura dramatizada en el cual resalta la importancia y la vigencia de la obra de Demetrio Ávila porque marca el dolor, la desesperación y la atrocidad. Aquí un fragmento de esta reseña:

La obra indica un río, pero en el transcurso se convierte en una tumba, mientras que las sirenas son los cuerpos de las distintas mujeres que han sufrido violencia sexual en un lugar aparentemente sin nombre: surcan un río de sangre, pero este montaje lo lleva más allá de sólo situarlo en lo que pareciera ser el norte del país como puede ser el Río Bravo (río mortal): puede ser cualquier lugar con abundante agua (Veracruz, Guerrero, Sinaloa, Tamaulipas) o un territorio árido (Durango, Estado de México, Morelos, San Luis Potosí), la violencia contra las mujeres es uno de los ríos de 
sangre que desembocan en un océano llamado México porque la corrupción, la muerte y la violencia hacen de México un océano infinito teñido de rojo por las atrocidades y la sangre. ${ }^{21}$

21 Juan Fernando Hernández García, “Océano”. Sinestesia Escénica. Revista Michoacana de Estudios de la Escena Contemporánea (2017). <https://sinestesiaescenica.wordpress.com/2017/12/04/oceano/ $>$. 


\section{Difusión Dramaturgias y Feminicidios en medios electrónicos}

En el presente apartado comento las actividades de difusión hechas con la ayuda de las tecnologías de la información y la comunicación; también comentaré acerca de las redes sociales que se administraron para la difusión de las lecturas dramatizada. La página web www.dramaturgiasyfeminicidios.com propone un espacio dedicado al proyecto de difusión con el propósito de divulgar las obras Los trazos del viento de Alan Aguilar, Lomas de Poleo. Morir con las alas plegadas de Pilo Galindo y Sirenas de Río de Demetrio Ávila.

Entre los lineamientos del Plan de Estudios de la Maestría en Literatura Mexicana Contemporánea, se puntualiza que como requisito para la obtención del grado de maestro debe desarrollarse un proyecto de difusión cultural que use como plataforma alguna tecnología de la información y la comunicación, apegado a estos lineamientos e intereses personales, hice la página web www.dramaturgiasyfeminicidios.com dedicada a la difusión de las obras seleccionadas.

La página cuenta con cinco pestañas distribuidas de la siguiente manera:

- Inicio.

- Dramaturgia de feminicidios.

- Entrevista a dramaturgos.

- Galería de Lecturas Dramatizadas.

- Ligas de interés.

- Contacto.

En el inicio de la página pueden leerse fragmentos de las obras seleccionadas para el proyecto de Dramaturgias y Feminicidios. Al final de cada texto hay un enlace para consultar las obras completas de Los trazos del viento, Lomas de Poleo y Sirenas de Río; además de los fragmentos 
de los textos, también está descrito el propósito de la página, así como los alcances pretendidos con la creación de la web. Quiero agradecer la generosidad de los dramaturgos Virginia Hernández, Pilo Galindo, Alan Aguilar y Demetrio Ávila por permitir que sus textos sean consultados y puedan bajarse desde la plataforma de https://www.dramaturgiasyfeminicidios.com/textos en el apartado titulado "Dramaturgia de Feminicidios".

La tercera pestaña "Entrevista con dramaturgos" es un acercamiento a la obra de los autores quienes, a pesar de la distancia, me brindaron la oportunidad de conocer el proceso creativo de las obras. En este apartado hay una breve semblanza de cada uno de los dramaturgos que acompaña a la entrevista. Una manera de contactar a Demetrio Ávila y a Virginia Hernández fue por medio de las redes sociales y, por esto, fue el medio para poder llevar a cabo la entrevista de manera virtual.

La entrevista con el dramaturgo Demetrio Ávila, quien es originario de Tampico, se hizo el 10 de octubre de 2017 vía correo electrónico, y la entrevista con la autora de La ciudad de las moscas, el 31 de enero de 2017 vía Facebook. Por fortuna, las entrevistas con Alan Aguilar Murrieta y Pilo Galindo las hice en un encuentro en la Ciudad de México el 3 de febrero de 2017 y en Ciudad Juárez, Chihuahua, el 13 de octubre de 2017, respectivamente.

En cada una de las entrevistas se descubren voces que necesitan replicarse. Son creadores que desde el teatro cuentan historias de horror sobre mujeres violentadas y crímenes de odio sin respuesta a las familias ante la pérdida madres, hijas o hermanas. Una de las inquietudes que se plantearon en las entrevistas fue el proceso creativo de cada una de las obras. Si bien cada autor tenía muy claro el génesis de cada texto, los cuatro dramaturgos coincidieron en la necesidad de contar un hecho que no les puede ser ajeno. En la actualidad, ya no sólo es la frontera y sus maquilas, ahora es Guerrero, Puebla, Durango, Michoacán, Ciudad de México y Estado de 
México, por mencionar algunos de los estados que han superado en cifras los feminicidios cometidos en Chihuahua. ${ }^{22}$

A continuación, haré una breve descripción de cada una de las obras seleccionadas, así como de cada dramaturgo entrevistado con el propósito de establecer un marco de referencia de las voces de los creadores.

Iniciaré con La ciudad de las moscas (2005) de Virginia Hernández quien amablemente contestó mis preguntas vía Facebook el día 31 de enero de 2017. La dramaturga originaria de Tepic y egresada de la Licenciatura en Literatura Dramática y Teatro de la UNAM presenta una visión apocalíptica, que es reforzada por los personajes alegóricos, así como el triángulo de poder entre Juárez, La mujer de Lot y Fausto ante la situación deplorable

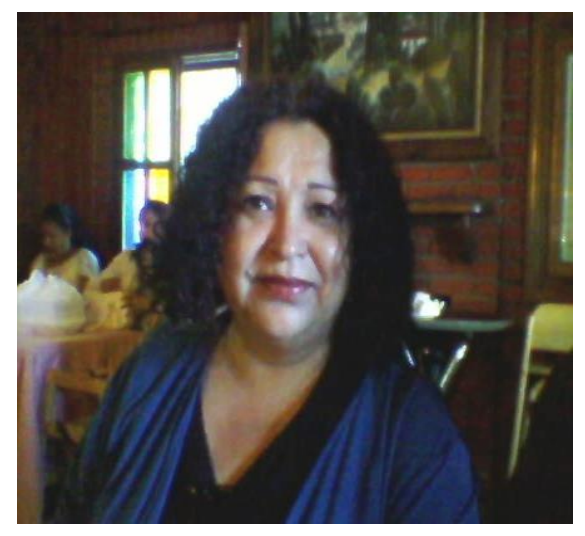

F 33 Virginia Hernández de la que son cómplices y testigos.

En la obra de Hernández, el zumbido de las moscas tiene una connotación imperante a los insectos como metáforas de las almas de las mujeres asesinadas. Este recurso simbólico de muerte y putrefacción es utilizado como presagio de la destrucción de Juárez. La autora hace referencia a Las moscas (1943) del dramaturgo francés Jean Paul Sartre, quien escribe este texto a partir de la resistencia amarga a la guerra, para retomar los hechos violentos en contra de las mujeres asesinadas en Ciudad Juárez.

\footnotetext{
${ }^{22}$ María Salguero, activista y geofísica elaboró un mapa interactivo en Google que retrata la geografía de los casos de feminicidio a partir de registros periodísticos. El mapa titulado "Feminicidios ocurridos en México reportados en la prensa" registra 2200 casos en 2017 y 963 casos en lo que va del 2018. El mapa puede consultarse en $\leq$ https://www.google.com/maps/d/u/0/viewer?mid=174IjBzPfl_6wpRHg5pkGSj2egE\&ll=22.952309595372313\%2C-101.4161826021728\&z=6> .
} 
Al cuestionarle a la dramaturga por qué escribir sobre feminicidios, llamó mi atención la importancia del teatro en su función social: vivir en la zona fronteriza del norte es enfrentarse a la violencia que impera en el país y a los crímenes de odio en contra de las mujeres:

- ¿Por qué escribir sobre feminicidios?

Porque representan un grupo social vulnerable, porque soy mujer y me lastima, porque soy socióloga y porque asumo el compromiso como dramaturga que se expresa a través del teatro, que en su función social, refleja la acción del ser humano y la increpa. Porque la literatura dramática es una herramienta para la reflexión y la acción. ${ }^{23}$

Si bien la reflexión es uno de los objetivos en la obra de la dramaturga, asumir un compromiso desde el teatro es una característica que comparten los entrevistados. Retomo la reflexión de Jean Duvignaud, en su libro Sociología del Teatro, quien señala que "cada sociedad engendra sus propias formas dramáticas". ${ }^{24}$ Es decir, toda sociedad tiende a exteriorizar su propia realidad. En este caso, la violencia de género es la que está de manifiesto desde aristas distintas en los cuatro creadores reunidos en Dramaturgias y Feminicidios.

La primera lectura dramatizada que hicimos fue Los trazos del viento de Alan Aguilar, trata la historia de Elena, Lucía y Laura; estas tres mujeres trabajan en una maquiladora en el norte del país. El regreso a casa y la búsqueda de la libertad son contadas a partir de pequeños monólogos evocadores de historias inconclusas de la infancia, el seno familiar y la añoranza exponen la fragilidad de sus vidas como un recuerdo de su vida antes de llegar a la maquiladora.

\footnotetext{
2323 Entrevista con Virginia Hernández hecha de manera virtual el 31 de enero de 2017. Publicada en $\leq$ https://www.dramaturgiasyfeminicidios.com/entrevistas-a-dramaturgos $>$.

${ }^{24}$ Jean Duvignaud, Sociología del teatro: ensayo sobre las sombras colectivas, Fondo de Cultura Económica, México, 1981, p. 519 .
} 


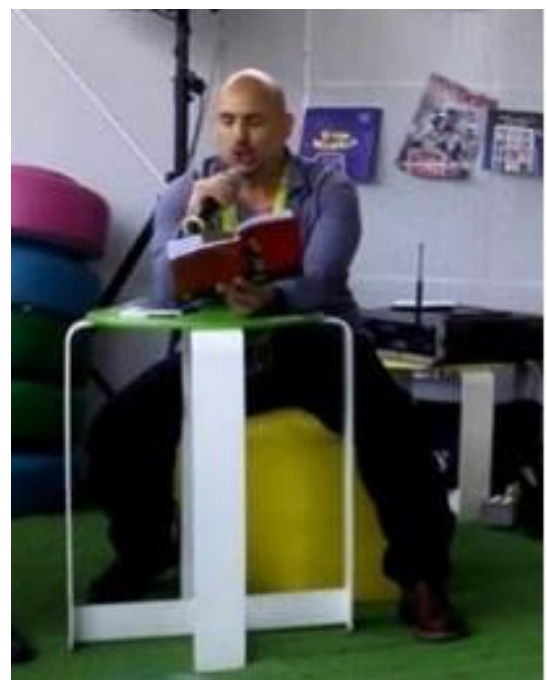

F34 Alan Aguilar

A partir de un lenguaje poético, las mujeres se remontan a su lugar de origen, cuentan historias que se repitieron una y otra vez en un espacio íntimo, seguro.

La entrevista con Alan Aguilar, egresado de la Licenciatura en Letras Hispánicas de la UNAM y de la Sogem, la hice el 3 de febrero de 2017 en la Ciudad de México. Mi inquietud del proceso creativo de Los trazos del viento surge a partir de la descripción de estas tres mujeres que aspiran a una mejor calidad de vida y cómo esos rostros evolucionaron en la construcción

dramática:

Lo que sí yo tenía muy claro era que quería denunciar lo que estaba pasando porque me parecía muy grave, triste y doloroso y que había que hablar de eso y en segundo lugar hacer homenaje, por lo tanto, para mí fue muy claro que los personajes tenían que ser una suerte de homenaje a las trabajadoras, a las víctimas. Lo que realmente era importante era valorar a las mujeres y que dejaran de ser un número porque en las estadísticas de feminicidios se volvieron rápidamente en un número; lo que quería era darles nombre y rostro de los personajes, que dejaran de ser estadísticas, números, que se volvieran rostros y nombres. ${ }^{25}$

Para el dramaturgo, puede denunciarse desde el teatro sin ser una extensión de la nota roja. El también poeta aclara que lo importante es la identidad de las mujeres violentadas: no son sólo cifras, sino historias que se denuncian por medio de un espacio teatral: la indiferencia de una sociedad sexista y clasista.

25 Entrevista con Alan Aguilar en la Ciudad de México el 3 de febrero de 2017. Publicada en $\leq$ https://www.dramaturgiasyfeminicidios.com/entrevistas-a-dramaturgos $>$. 
Cuando iniciamos la planeación de las lecturas dramatizadas, Sirenas de Río no estaba dentro del corpus seleccionado, sin embargo, recuerdo que cuando leí el texto por primera vez me pareció estremecedora la historia de la niña en busca de su madre. La historia aquí tomaba otro giro: las sirenas no seducen con su canto, sino que son víctimas que la violencia arrancó. Aquí el río somos todos, también somos cómplices y verdugos como sociedad indiferente a los hechos. Así, en una cuarta o quinta relectura del texto de Demetrio Ávila, reconsideré incorporarla al trabajo de las lecturas dramatizadas.

El acercamiento con el dramaturgo tampiqueño fue vía Facebook. Al explicarle el proyecto de difusión, amablemente concedió a contestarme una serie de preguntas el 10 de octubre de 2017. En la entrevista me confiesa que en una ciudad ha sido testigo de que la violencia llegó de manera silenciosa y ha hecho a los habitantes susurrar porque no saben quién come a su lado. ${ }^{26}$ Escribir de ese

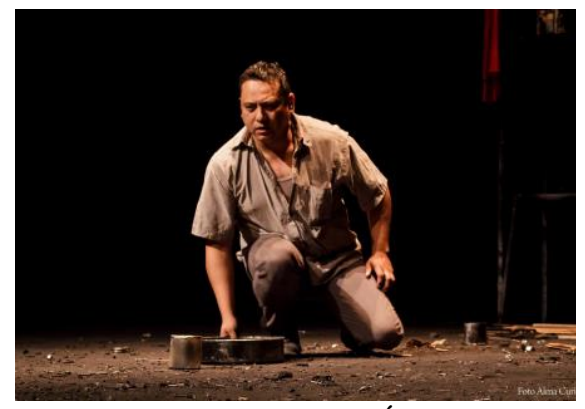

F35 Demetrio Ávila espacio que ha perdido identidad, de un lugar que ha sido secuestrado por la violencia y el desencanto:

Sirenas de Río es un texto donde quise desde mi trinchera darle voz a las mujeres que han sido violentadas, marginadas, asesinadas, en un río que es frontera y cómplice. De esta violencia nos volvemos víctimas y verdugos. Esta violencia nos va dejando heridas sin cauterizar en nuestros actos cotidianos y nos vuelve indolentes a pocos pasos de la indiferencia. ${ }^{27}$

Demetrio Ávila no es el único dramaturgo del norte para el que la violencia ha sido un tema en su obra dramatúrgica. Edeberto Galindo también escribe desde la indignación por ser testigo de la indiferencia de las autoridades por resolver los feminicidios en Ciudad Juárez. Este hecho hizo

\footnotetext{
${ }^{26}$ Entrevista con Demetrio Ávila, op. cit.

${ }^{27}$ Ibid.
} 
que se focalizara en la década de 1990 en esta ciudad fronteriza debido al amarillismo y oportunismo de algunos medios de comunicación.

El encuentro con el dramaturgo se hizo en el marco del XXIII Congreso Internacional de Investigación Teatral de la Asociación Mexicana de Investigación Teatral (AMIT) titulado "Las fronteras en el teatro. Condición, contexto e intersecciones” y se llevó a cabo del 11 al 13 de octubre de 2017 en la Universidad Autónoma de Ciudad Juárez.

Con una trayectoria teatral de más de 30 años,

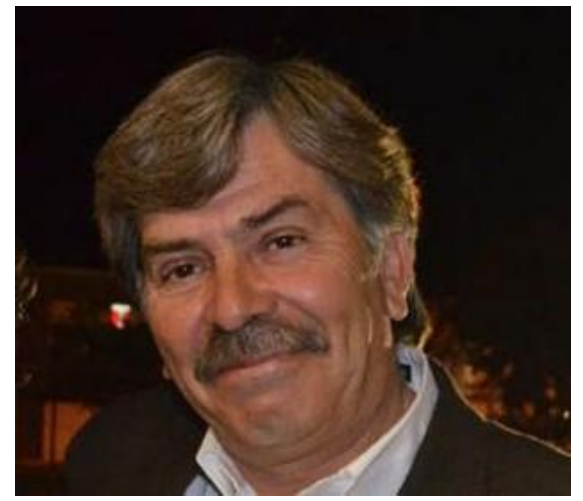

F 36 Edeberto"Pilo" Galindo
Edeberto "Pilo" Galindo fue acreedor al premio Chihuahua de Literatura 2002 en el género de Dramaturgia por la obra Lomas de Poleo. Morir con las alas plegadas. Además, ha sido miembro del Sistema Nacional de Creadores del Fonca de 2009 a 2012. Obtuvo el premio de Dramaturgia Juan Ruiz de Alarcón en 2015. Sus obras han sido incluidas en diversas antologías, entre las cuales se encuentran: Dramaturgia del Norte, compilación de Enrique Mijares (FORCA del Noreste, 2003) y Cinco Dramaturgos Chibuahuenses (Gobierno Municipal de Ciudad Juárez, 2005).

La entrevista se llevó a cabo el 13 de octubre de 2017en la Universidad Autónoma de Ciudad Juárez. A Pilo Galindo le interesa escribir de lo que sucede en Juárez, casi en un sentido antropológico, me confiesa, pues para él los asesinatos de mujeres en esta zona fronteriza lo conmovió y lo perturbó. De ahí surge esa necesidad de alzar la voz con Lomas de Poleo. Al preguntarle a propósito del proceso creativo de la obra me cuenta:

Pude haber hecho una obra tremendista, una obra hiperrealista, pero recurrí a esta figura literaria cuasi poética de las chicas hablando del maquillaje, esperando la luz del día como la esperanza. Creo que esos personajes son niñas y están en un limbo y no saben dónde están, no saben qué va 
a pasar y no quise cometer otra atrocidad en el teatro con ellas y por eso usamos estas figuras literarias y cree estos personajes dolientes, sufridos, pero con esperanza. No saben dónde están, no saben qué paso, pero, cuando al final lo descubren, tienen una actitud valiente las chicas y sobre todo Érika. ${ }^{28}$

En Lomas de Poleo, las protagonistas son casi niñas. La violencia ejercida sobre ellas no es sólo de sus victimarios, sino de las autoridades, esta violencia se normaliza por la indiferencia de un sistema corrupto, pero son sólo cifras, números que ocupan un nombre de una madre, una hija o una esposa.

El diálogo con estos cuatro dramaturgos surge a partir de explorar el proceso creativo de cada obra seleccionada. Las voces de Virginia Hernández, Alan Aguilar, Demetrio Ávila y Pilo Galindo apelan a la necesidad de alzar la voz en contra de los feminicidios en el país. Los crímenes de odio contra las mujeres ya no son exclusivos de una zona, los índices cada vez van más al alza como lo indica María Salguero en el mapa "Feminicidios ocurridos en México reportados en la prensa". Las entrevistas con estos creadores son testimonios de la diversidad de historias que nunca hay que dejar de contar a partir de diferentes voces que emanan surgen desde la literatura dramática.

La cuarta pestaña de www.dramaturgiasyfeminicidios.com se titula "Galería de lecturas dramatizadas", que a su vez tiene una liga para visitar las fotos de cada una de las lecturas dramatizadas en el orden en el que se presentaron. Las fotos de Los trazos del viento y de Lomas de Poleo fueron tomadas por Pedro González quien se integró al equipo como fotógrafo en las presentaciones y ensayos de ambas obras.

28 Entrevista con Pilo Galindo en Ciudad Juárez el 11 de octubre de 2017. Publicada en $\leq$ https://www.dramaturgiasyfeminicidios.com/entrevistas-a-dramaturgos $>$. 
La quinta pestaña se titula "Sitios de interés" https://www.dramaturgiasyfeminicidios.com/sitios-de-interes apartado que tiene como propósito difundir algunas ligas de páginas que pueden resultar relevantes para aquellos que visiten la página y quieran profundizar en el tema de los feminicidios a partir de artículos de investigación, notas periodísticas, reseñas de obras de teatro entre otros enlaces sugeridos. Otro de los objetivos de este apartado es que se extienda esta lista con las aportaciones y sugerencias de las personas que visiten la página.

La sexta y última pestaña de la web es "Contacto" en donde se puedan hacer comentarios para mejorar la información proporcionada. Este es un panorama general de los contenidos que integran www.dramaturgiasyfeminicidios.com de tal manera que sea un espacio para la consulta de textos dramáticos, entrevistas con dramaturgos, sitios de interés e intercambio de ideas a propósito de los feminicidios en nuestro país. 


\section{Presentación de www.dramaturgiasyfeminicidios.com en la Universidad Autónoma de}

\section{Ciudad Juárez}

El 12 de octubre de 2017 tuve la oportunidad de presentar una primera versión de www.dramaturgiasyfeminicidios.com en el Congreso "Las fronteras en el teatro. Condición, contexto e intersecciones" de la Asociación Mexicana de Investigación Teatral (AMIT) en la Universidad Autónoma de Ciudad Juárez, gracias a la invitación de la Mtra. Rocío Galicia, investigadora titular del Centro de Investigación Teatral Rodolfo Usigli (CITRU).

La mesa moderada por la Dra. Susana Báez estaba dedicada a la presentación de las nuevas publicaciones en al ámbito teatral. Entre los integrantes de esta mesa estaban María Fernández Aragón quien tradujo y presentó “Tragedia y Teatro dramático” de Hans-Thies Lehman, Roxana Rodríguez Ortíz presentó "Hospitalidad y ciudadanía. De Platón a Benhabib" de las

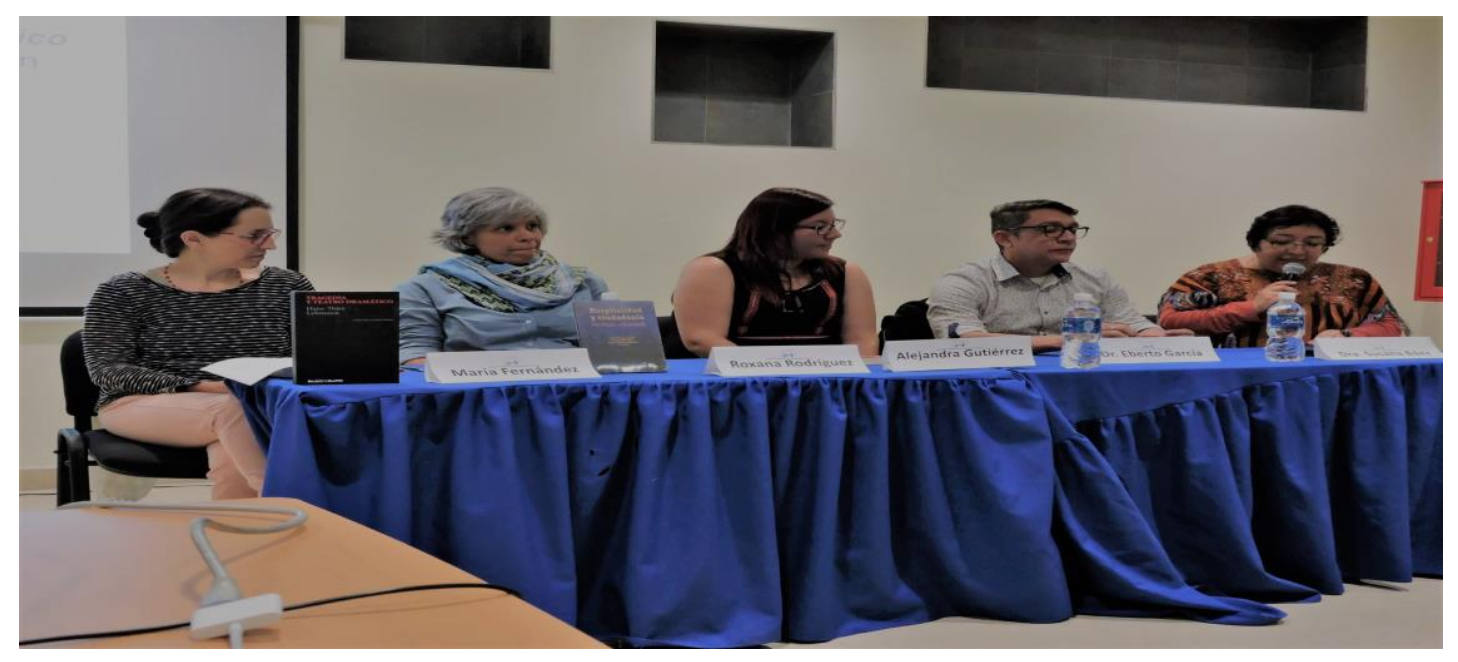

F37 Mesa dedicada a las nuevas publicaciones teatrales en la Universidad Autónoma de Ciudad Juárez 
compiladoras Mariela Oliva Ríos, Evelia Artega Conde y Roxana Rodríguez Ortíz, y por último "Estaciones Teatrales” del investigador cubano Eberto García Abreu.

En la presentación pude hablar del proceso creativo de la página, así como el objetivo de esta plataforma. Entre los propósitos de hacer www.dramaturgiasyfeminicidios.com están promover los textos de estos dramaturgos que tratan el tema de los feminicidios en México y analizarlas. Las obras de Virginia Hernández, Alan Aguilar, Demetrio Ávila y Pilo Galindo deben repercutir en la sociedad porque este tema concierne a todos sus habitantes. Por esta razón, es urgente y necesario acercamientos a estas dramaturgias que hablan de feminicidios cuyos rostros han perdido identidad.

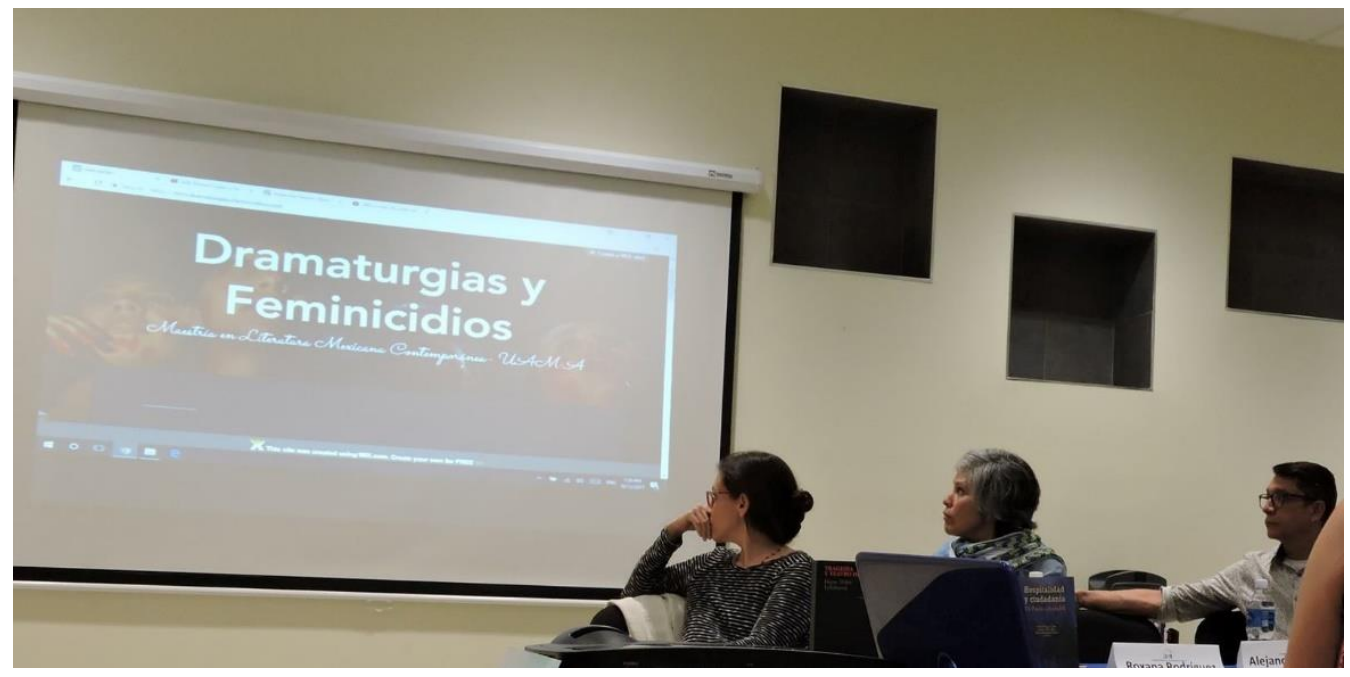

F38 Presentación de www.dramaturgiasyfeminicidios.com en la Universidad Autónoma de Ciudad Juárez 


\section{Consideraciones finales}

La difusión debe pensarse de forma global, el objetivo de difundir una obra o un autor es que llegue al mayor número de personas sin importar su condición sociopolítica. Difundir es crear estrategias acordes a las necesidades y exigencias de una sociedad que utiliza nuevas tecnologías de información y plataformas tecnológicas como medios de comunicación para llegar a un público más amplio.

La labor de difusión también es la de crear espacios para dar voz a los creadores e investigadores para establecer redes sólidas y dinámicas para aportar saberes y conocimientos. Un creador es un observador de su tiempo, un testigo de las circunstancias que han influido en su obra, el proceso creativo se nutre de los muchos contextos, de los "muchos Méxicos" que señalaba Víctor Hugo Rascón Banda.

En esa diversidad de escenarios, el teatro se ha personalizado con cada sociedad, por ende, el arte dramático va más allá de la literatura escrita, pues las diferentes prácticas teatrales han estado en contacto con acontecimientos sociales en la historia de la humanidad. Retomo a Jean Duvignaud quien señala que "cada sociedad engendra sus propias formas dramáticas", ${ }^{29}$ es decir, toda sociedad tiende a exteriorizar su propia realidad, de ahí que el teatro sea considerado una paradoja pues abre una posibilidad de elección en un espacio y un tiempo de excepción que no ofrece la realidad.

La realidad no siempre tiene respuestas. En una representación teatral todo se convierte en un signo y las interrogantes se plantean en un escenario vacío para contar historias. Para

\footnotetext{
${ }^{29}$ Jean Duvignaud, op.cit.
} 
Tadeus Kowzan, "el espacio es una zona particularmente poblada de vacíos”. ${ }^{0}$ Por lo tanto, la unión de elementos espaciales y temporales en La ciudad de las moscas, Los trazos del viento, Lomas de Poleo y Sirenas de Río están construidas en espacios transgredidos por vacíos e incertidumbres en la maquiladora, en la escuela, en el ministerio público, en el mar, en el desierto, en la parada de autobús, en el hospital, en el anfiteatro, en la casa; estos son escenarios de una realidad que no brinda respuestas a las familias que han perdido madres, hijas, hermanas y esposas para convertirse en números.

El objetivo de Dramaturgias y Feminicidios es la difusión de obras de dramaturgos mexicanos cuya realidad los ha convertido en testigos de los crímenes de odio en contra de las mujeres en el país. Las actividades descritas en este informe son un primer acercamiento al proceso creativo de las lecturas dramatizadas y de la página web. Sin embargo, el propósito de este proyecto de difusión es dar continuidad al diálogo con los dramaturgos y creadores que han explorado el tema de los feminicidios desde las artes escénicas.

Me siento satisfecha con los resultados de Dramaturgias y Feminicidios, pues el proyecto rebasó las expectativas que se tenían en un principio, no obstante, me parece que hay mucho trabajo por hacer, pues son muchas voces las que necesitan ser escuchadas desde el teatro, son muchos las historias que faltan por contar, pero lo más importante hay muchas víctimas que necesitan tener un nombre e identidad.

\footnotetext{
30 Tadeusz Kowzan, Literatura y espectáculo, trad. de Manuel García Martínez, Taurus, Madrid, 1992 (Taurus Humanidades. Teoría y crítica literaria, 332), p. 109.
} 


\section{Referencias}

Bobes Naves, María del Carmen, Teoría del teatro, Arco Libros, Madrid, 1997.

Dubatti, Jorge, Introducción a los estudios teatrales, Libros de Godot, México, 2011.

Duvignaud, Jean, Sociología del teatro: ensayo sobre las sombras colectivas, Fondo de Cultura Económica, México, 1981.

Galicia, Rocío, "Giros conceptuales en el archipiélago teatral mexicano: tres presentes teóricos”. Revista Gestos, Gestos. Teoría y crítica del teatro hispánico 55 (28), pp. 97-114.

, y Gabriel Yépez (comps.), Casi muerte, casi vida. Manifestaciones teatrales en la frontera norte de México, Libros de Godot-Instituto Nacional de Bellas Artes-Centro Nacional de Investigación, Documentación e Información Teatral Rodolfo Usigli-Consejo Nacional para la Cultura y las Artes, México, 2011.

Kowzan, Tadeusz, Literatura y espectáculo, trad. de Manuel García Martínez, Taurus, Madrid, 1992 (Taurus Humanidades. Teoría y crítica literaria, 332).

Márquez, Alejandra, “Allá derecho encuentras algo”, en Oswaldo Estrada (ed.), Mujeres y violencia en tres narrativas de la frontera en Senderos de la violencia Latinoamericana y sus narrativas armadas, Albatros Ediciones, Valencia, 2011 (Serie Palabras de América, 1)

Mijares, Enrique (ed.), Dramaturgia del norte: antología, Fondo Regional para la Cultura y las Artes del Noroeste, Monterrey, 2003.

- Hotel Juárez: Dramaturgia de Feminicidios, presentación de Victoria Martínez y Rocío Galicia, Universidad Juárez del Estado de Durango, campus Durango-Espacio Vacío/Union College, 2008 (Colección Teatro de Frontera, 21-22).

Dubatti, J. (2009). Concepciones de teatro: Poéticas teatrales y bases epistemológicas. En https://saquenunapluma.wordpress.com/2011/05/31/concepciones-de-teatro-poeticasteatrales-y-bases-epistemologicas-por-jorge-dubatti/ [consultado el 11 de octubre de 2016] 
Hemerografía web

Álvarez, Benjamín, “Abordan impacto de feminicidio en teatro". Reforma (2016), < https://www.reforma.com/aplicacioneslibre/articulo/default.aspx?id=763836\&md5= 74aab738727b34b0523b4e56a0dfaccf\&ta=0dfdbac11765226904c16cb9ad1b2efe $>$.

Arrieta, Diana, “Las muertas de Juárez: ¿Un caso resuelto u oculto?”. Borderzine. Reporting Across Fronteras (2013), < $\underline{\text { http://borderzine.com/2013/01/las-muertas-de-juarez- } \% \text { C2 } \% \text { BFun- }}$ caso-resuelto-u-oculto/>.

Báez, Susana e Ivonne Ramírez et al., “Lomas de Poleo: de lecturas y marginación”. El cotidiano 164 (2010), pp. 64-73. <http://www.redalyc.org/html/325/32515894010/>.

Bobes Naves, María del Carmen, “Teatro y semiología”. Arbor 177: 699-700 (2004), pp. 497-508. $<\underline{\text { http://arbor.revistas.csic.es/index.php/arbor/article/view/591>. }}$

Denis, Daphnée y Alma Rodríguez, Las voces de las silenciadas, supl. especial de El País (2018), < https://elpais.com/tag/c/63d2707764492e98c02d7e1abd8f9bc9)>.

Gutiérrez Rebelo, Alejandra, "Entrevistas con dramaturgos”. Dramaturgias y Feminicidios (2018), en < https://www.dramaturgiasyfeminicidios.com/entrevistas-a-dramaturgos $>$.

Hernández García, Juan Fernando, “Océano” [reseña sobre la lectura dramatizada de Sirenas de río de Demetrio Ávila]. Sinestesia Escénica. Revista Michoacana de Estudios de la Escena Contemporánea (2017), < $\underline{\text { https://sinestesiaescenica.wordpress.com/2017/12/04/oceano/> }}$.

Juaritos Literario: Cartografía Literaria de Ciudad Juárez. Proyecto de Investigación Literaria e Intervención Ciudadana (2018), <https:/ juaritosliterario.com/>.

Lagarde y de los Ríos, Marcela, “Antropología, feminismo y política: violencia feminicida y derechos humanos de las mujeres”, en Margaret Louise Buulen y María Carmen Díez Mintegui (coords.), Retos teóricos y nuevas prácticas, Ankulegi, San Sebastián (Esp.), 2008, pp.. < https://www.ankulegi.org/wp-content/uploads/2012/03/0008Lagarde.pdf. $>$.

Mijares, Enrique, "Realismo virtual en la dramaturgia mexicana", Latin American Theatre Review $\begin{array}{lll}31: 1 & \text { (1997), } & \text { pp. }\end{array}$ < $\underline{\text { https://journals.ku.edu/index.php/latr/article/viewFile/1182/1157> }}$. 
Monárrez Fragoso, Julia, "Elementos de análisis del feminicidio sexual sistémico en Ciudad Juárez para su viabilidad jurídica", en Seminario Internacional: Feminicidio, Derecho y Justicia. México, D.F., 8 y 9 de diciembre. Memorias, Cámara de Diputados, México, 2004, pp. 1-19. <http://mujeresdeguatemala.org/wp-content/uploads/2014/06/Elementos-delfeminicidio-sexual-siste $\%$ CC $\% 81$ mico.pdf $>$.

Observatorio Ciudadano Nacional del Feminicidio, 2017, $<$ http://observatoriofeminicidio.blogspot.com/p/quienes-somos.html $>$.

Salguero, María, Mapa de feminicidios en México reportados por la prensa, 2018, <https://www.google.com/maps/d/u/0/viewer?mid=174IjBzP-

fl 6wpRHg5pkGSj2egE\&ll=22.952309595372334\%2C-101.4161826021728\&z=6>. 